\title{
Chemical kinetic study of triptane (2,2,3-trimethylbutane) as an anti-knock additive
}

\author{
Nour Atef*, Gani Issayev, Samah Y. Mohamed, Ahmed Najjar, Zhandong Wang, \\ Jui-Yang Wang, Aamir Farooq, S. Mani Sarathy**
}

King Abdullah University of Science and Technology (KAUST), Clean Combustion Research Center, Physical Sciences and Engineering Division, Thuwal, Saudi Arabia

\section{A R T I C L E I N F O}

\section{Article history:}

Received 29 April 2019

Revised 11 June 2019

Accepted 4 September 2019

\section{Keywords:}

Triptane

Combustion model

Alternative isomerization

Heptane isomer

Engine knock

\begin{abstract}
A B S T R A C T
2,2,3-Trimethylbutane (i.e., triptane) is a potential gasoline octane booster with a research octane number (RON) of 112. Recent studies showed that it can be catalytically produced with high selectivity from methanol $\left(\mathrm{CH}_{3} \mathrm{OH}\right)$ and dimethyl ether (DME), which presents a promising route for utilizing biomass derivatives as transportation fuels. Understanding the ignition properties of triptane at engine relevant conditions is crucial for its further evaluation.

In this work, a detailed kinetic model for triptane combustion is developed and validated. The rate rules for the low-temperature oxidation reactions are evaluated based on quantum chemistry calculations from literature, and thermochemical properties of all the species are assessed based on new thermodynamic group values with careful treatment of gauche interactions. In addition, alternative isomerization pathways for peroxy-alkylhydroperoxide species $(\mathrm{OOQOOH})$ are incorporated in the model.

The model is validated against new ignition delay data from facilities at King Abdullah University of Science and Technology (KAUST): rapid compression machine (RCM) experiments at pressures of 20 and 40 bar, equivalence ratios of 0.5 and 1 and across a temperature range of 620 to $1015 \mathrm{~K}$, and shock tube experiments at 2 and 5 bar, 0.5 and 1 equivalence ratio and over $1000-1400 \mathrm{~K}$. Moreover, the model prediction of various species is compared against species profiles from jet stirred reactor experiments at three equivalence ratios $(0.5,1$ and 2$)$ at atmospheric pressure. Finally, triptane is compared with its less branched isomers, $n$-heptane and 2-methylhexane, to evaluate the effect of branching on fuel reactivity and importance of alternative isomerization pathway.
\end{abstract}

(c) 2019 The Combustion Institute. Published by Elsevier Inc. All rights reserved.

\section{Introduction}

Petroleum derived gasoline fuels are widely used in light-duty transportation, and improving the efficiency of spark ignition engines which can be achieved by improving gasoline antiknock quality $[1,2]$. Biofuels are the single largest renewable energy source today, providing $10 \%$ of world primary energy supply, as reported by the International Energy Agency (IEA). Biofuels of the second and third generations are attractive to meet the increasing demand for clean and sustainable energy [3]. The most common types of biofuels in use today are ethanol and biodiesel. Ethanol is usually blended with conventional gasoline at 5-10\% for spark ignition engines where it suppresses knock and allows increasing the engine compression ratio and hence its efficiency [4]. However,

\footnotetext{
* Corresponding author. Present address: National Fire Laboratory, Institute for Research in Construction, National Research Council Canada, Ottawa, Canada.

** Corresponding author.

E-mail addresses: nour.elsagan@nrc-cnrc.gc.ca, nour.atef@kaust.edu.sa (N. Atef), mani.sarathy@kaust.edu.sa (S.M. Sarathy).
}

several limitations hinder increasing the percentage of ethanol like its higher latent heat of vaporization relative to hydrocarbons and low calorific value. In addition, excessive blending ethanol in gasoline may not always offer reduction in lifecycle $\mathrm{CO}_{2}$ emissions, and lower blend fractions can offer optimal efficiency [5]. Higher alcohols have been proposed as blending components with gasoline fuels, but their production costs and sustainability are notably less attractive than for ethanol [6].

Non-fermentation based thermal and catalytic processes are regarded as a promising route for converting biomass into new fuels. It can be applied to produce targeted bio-derived products that are compatible with the tailored fuel applications, in both quality and quantity [3]. Moreover; the selectivity of these processes is progressively increasing. 2,2,3-trimethylbutane (triptane) can be catalytically produced from bio-derived dimethyl ether (DME) at high selectivity. Simonetti et al. [7,8] showed the synthesis of triptane and iso-butane by reacting dimethyl ether over large-pore acidic zeolites at relatively low temperatures $\left(180-220^{\circ} \mathrm{C}\right)$ and pressures (60-250 kPa of DME) at high selectivity. However, the hydrogen deficiency of DME homologation to alkane products results in the 
formation of unsaturated residues (e.g., alkylated aromatics such as hexamethylbenzene (HMB)), which decreases the yield of the desired alkanes and may cause catalyst deactivation. Later, Schaidle et al. [9] improved yield of this catalytic process by utilizing a Cu-modified zeolite catalyst that is able to incorporate hydrogen from gas-phase $\mathrm{H}_{2}$ cofed with dimethyl ether into the desired branched alkane products, while maintaining the high $\mathrm{C}_{4}$ and $\mathrm{C}_{7}$ carbon selectivity of the parent zeolite. Triptane is classified as a potential gasoline bio-additive, where it has desirable properties, similar to conventional gasoline, of boiling and melting points, corrosion properties, toxicity, flammability and flash point [10].

Understanding the combustion chemistry of triptane can help evaluate its applicability as an antiknock improver to gasoline in spark ignition engines. The research octane number (RON) of triptane is 112. Detailed chemical kinetic models are a tool for understanding the behavior of fuels in different combustion devices, such as idealized homogeneous reactors like shock tubes and jet stirred reactors or more non-idealized systems like engines. Westbrook et al. [11] developed combustion kinetic models for heptane isomers, including triptane; however, the model was limited to the high temperature reaction classes. Combustion in advanced combustion engines and conventional knock phenomenon are governed by low temperature reactions, so reaction classes important at lower temperatures should be included in kinetic modeling.

This work focuses on modeling the combustion kinetics of triptane. Following our recent iso-octane model [12], the present model incorporates recent rate rules from literature for the low temperature classes [13-16]. In addition, alternative isomerizations for peroxy-alkylhydroperoxide species $(\mathrm{OOQOOH})$ are added in a similar way to recently developed models [12,17-19]. The model is then compared against the following experimental data:

- Ignition delay time data from rapid compression machine at 20 and 40 bars and two equivalence ratios; 0.5 and 1 .

- Ignition delay time data from shock tube experiments at 0.5 and 1 equivalence ratios, low pressures of 2 and 5 bars and high temperatures of 1000 to $1400 \mathrm{~K}$.

- Jet stirred reactor speciation data at atmospheric pressure and three equivalence ratios of $0.5,1$ and 2 .

Finally, simulations of triptane and its less branched isomers; $n$-heptane [20] and 2 methyl-hexane [19] are presented to investigate the effect of branching on fuel reactivity and importance of alternative isomerization.

\section{Computational methods}

The triptane sub-model is built in hierarchical manner based on AramcoMech 2.0 [21] for $C_{0}-C_{4}$ species, pentane isomers submodel from Bugler et al. [18] and $n$-hexane from Zhang et al. [17]. The model also includes sub-mechanisms for $n$-heptane [20], isooctane [22] and toluene [23].

High temperature and low temperature reaction classes were investigated to determine the species involved in triptane combustion chemistry. Then the thermochemical properties of those species were evaluated using the group additivity method [24]. Finally rate rules were assigned for all reaction classes. The complete mechanism consists of 7323 reactions and 1785 species, with 223 reactions and 37 species specific to the triptane sub-mechanism. Details about the thermochemistry and implemented rate parameters are discussed in the next sub-sections.

\subsection{Thermochemistry}

Thermochemical data are used for calculating the mixture temperature and the rates of reversible reactions through the
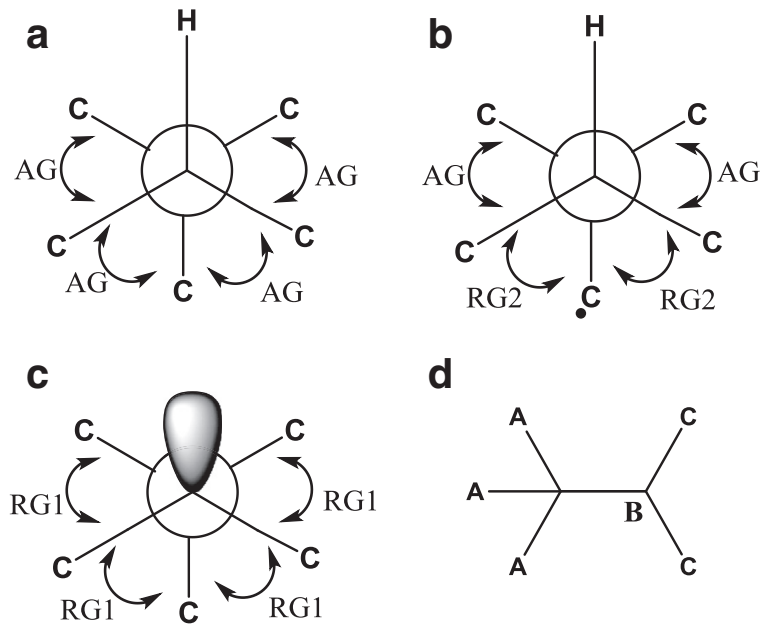

d

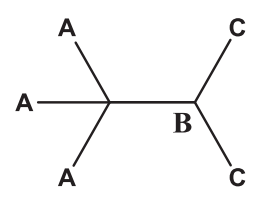

Fig. 1. Newman projections showing gauche interactions for (a) the triptane molecule along the tertiary-quaternary bond and (b) RG2 (c) RG1 radical interactions; and (d) structure of triptane with site labels.

equilibrium constant;

$K_{e q}=\frac{k_{f}}{k_{b}}=\exp \left(\frac{-\Delta G}{R T}\right)$

where $K_{e q}, k_{f}$ and $k_{b}$ are equilibrium constant, rates of forward and backward reactions respectively, $\Delta \mathrm{G}$ is the change in the Gibb's free energy of chemical reaction.

In this work, the thermochemical data of all species involved in the triptane oxidation sub-mechanism were evaluated using Benson's group additivity method [24], as implemented in THERM software [25]. The new group values proposed by Burke et al. [26] and Simmie and Somers [27] were used. In addition, accurate treatment of gauche interactions was considered based on the work of Sabbe et al. [28]. Based on the Newman projection shown in Fig. 1a, triptane has 4 alkane gauche (AG) interactions. However, the calculations done by Sabbe et al. [28] showed that 5 gauche interactions should be considered along the tertiary-quaternary bond. Accordingly, 5 gauche interactions are accounted for in triptane.

For radicals, Sabbe et al. [28] classified them based on the radical site into i) RG1 (shown in Fig. 1c), where the interaction between two sp3-hybridized carbon groups, one of which is connected to the radical site, and ii) RG2 (shown in Fig. 1b), where the interaction is between an sp2-hybridized and an sp3-hybridized carbon groups. According to their calculation [28], both RG1 and RG2 increase the heat of formation of the species; however their contribution is less compared to AG by $40 \%$ and $76 \%$, respectively. The current THERM data base doesn't include RG1 or RG2 groups; hence RG2 is implemented as full AG while RG1 interaction is neglected. Triptane has three radical sites as seen in Fig. 1d; 2 primaries (A and C) and 1 tertiary. Applying the rules of Sabbe et al. [28]; three and five gauche interactions are considered for the primary and tertiary radicals respectively. More details about the gauche interaction considerations in ethers and olefins can be found in [12].

\subsection{Chemical kinetic mechanism}

Following the work of Sarathy et al. for 2-methylalkanes [29] and other branched alkanes [30-32], 29 reactions classes were included in the triptane sub-model. These are sub-classified into high- and low-temperature classes. The high temperature reactions include formation of alkyl radicals from the fuel, their decomposition to smaller radicals and alkenes, and subsequent alkene 


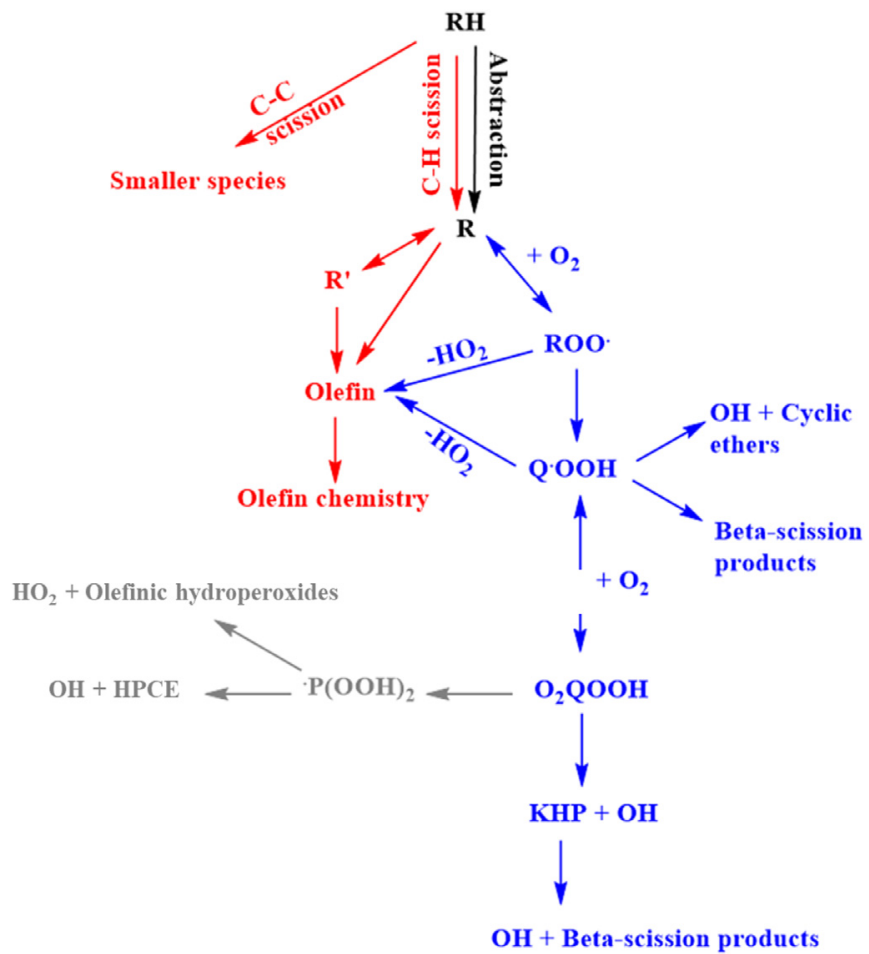

Fig. 2. Major classes involved in alkanes kinetic models. Red, blue and gray represent classes of high-temperature, low-temperature and alternative isomerization pathways; respectively.(For interpretation of the references to colour in this figure legend, the reader is referred to the web version of this article.)

chemistry; these are represented by 9 reaction classes. The lowtemperature chemistry is more complicated, involving the successive addition of molecular oxygen to alkyl radicals and subsequent intramolecular $\mathrm{H}$-atom migration of peroxy radicals. The low temperature scheme is comprised of 20 reaction classes. Moreover, alternative isomerization pathway for peroxy-alkylhydroperoxide species (OOQOOH) are added to the model. Major classes in the kinetic model are shown in the scheme presented in Fig. 2. The next sub-sections elaborate more about several important reaction classes included in the model and corresponding rate coefficient estimates. The remaining reaction classes are described in the Supplementary material.

\subsubsection{Unimolecular fuel decomposition}

This class involves breaking down the $\mathrm{C}-\mathrm{C}$, or $\mathrm{C}-\mathrm{H}$ bond in the fuel molecule. The rate rules used by Westbrook et al. [33] are adopted for triptyl $+\mathrm{H}$ reactions, where a rate constan of $10^{14} \mathrm{~cm}^{3} \mathrm{~s} / \mathrm{mol}$ is used. In case of $\mathrm{C}-\mathrm{C}$ cleavage, rate rules in analogy with iso-octane [12] were used. Activation energies $\left(E_{a}\right)$ were corrected using the bond dissociation energies (BDE) of iso-octane and triptane, based on the Evans-Polanyi [34] correlation where $\alpha$ equals to 1.477 ;

$E_{\text {atriptane }}=E_{a, \text { iso-octane }}+\alpha\left[B D E_{\text {triptane }}-B D E_{\text {iso-octane }}\right]$

The BDE of iso-octane were taken from the study by Ning et al. [35], while the BDE of triptane were calculated in this study at CBS-QB3// B3LYP/6-311++G(2df,2pd) level of theory using Gaussian09 [36] (more details in Supplementary material). Figure 3 shows the BDE for both molecules.

However, the rate constant of breakage of secondary-tertiary bond in triptane to produce iso-propyl (IC3H7) and tert-butyl (TC4H9) was multiplied by a factor of 2.5 to better match the high temperature shock tube experiments. Further discussion is provided in Section 5.
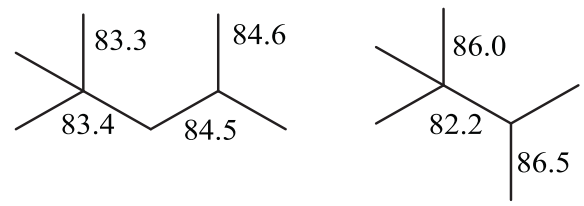

Fig. 3. Molecular structure and bond dissociation energies in $\mathrm{kcal} / \mathrm{mol}$ of $\mathrm{C}-\mathrm{C}$ bonds in iso-octane (left) [35] and triptane (right) (this work).<smiles>[2H]C([2H])([2H])[P+2]P</smiles>

Fig. 4. Carbon sites in triptane labeled according to the NNN methodology.

\subsubsection{H-atom abstraction from the fuel}

Rate constants for $\mathrm{H}$-atom abstraction by $\mathrm{O}, \mathrm{O}_{2}, \mathrm{HO}_{2}, \mathrm{H}, \mathrm{CH}_{3}$, $\mathrm{CH}_{3} \mathrm{O}_{2}, \mathrm{C}_{2} \mathrm{H}_{3}, \mathrm{CH}_{3} \mathrm{O}$ and $\mathrm{C}_{2} \mathrm{H}_{5}$ were added based on the rate rules suggested by Sarathy et al. [29]. For H-atom abstraction by $\dot{\mathrm{OH}}$ radicals, the adopted rate coefficients are experimentally-derived based on the next-nearest-neighbor (NNN) carbon atoms. Figure 4 shows the three radical sites in triptane according to the NNN nomenclature, where $\mathrm{P}$ and $\mathrm{T}$ stand for the nature of the carbon atom (primary and tertiary) and the subscript refers to the number of other carbons bonded to the NNN $\mathrm{C}$ atoms of the $\mathrm{C}-\mathrm{H}$ bond of interest.

The rate parameters used for $\mathrm{P}_{2}$ and $\mathrm{P}_{3}$ are adopted from the work done by Sivaramakrishnan and Michael [37] who studied the kinetics of $\mathrm{H}$-atom abstraction by $\dot{\mathrm{O}} \mathrm{H}$ radicals from five saturated hydrocarbons in shock tube and provided rate rules for $\mathrm{H}$-atom abstraction from $\mathrm{P}_{1}, \mathrm{P}_{2}, \mathrm{P}_{3}, \mathrm{~S}_{00}, \mathrm{~S}_{01}, \mathrm{~S}_{11}, \mathrm{~T}_{000}$ and $\mathrm{T}_{002}$ sites.

Another work done by Liu et al. [38] focused on providing experimentally-derived rates for different tertiary sites. They measured the rates of $\mathrm{H}$-abstraction by $\dot{\mathrm{OH}}$ from 9 large branched alkanes; 2-methyl-3-ethyl-pentane, 2,3-dimethylpentane, 2,2,3-trimethylbutane, 2,2,3-trimethyl-pentane, 2,3,4trimethylpentane,3-ethyl-pentane, 2,2,3,4-tetramethyl-pentane, 2,2-dimethyl-3-ethyl-pentane, and 2,4-dimethyl-3-ethyl-pentane. Their measured rates were then combined with data from Sivaramakrishnan and Michael [37] and Badra and Farooq [39] and abstraction rate parameters from $\mathrm{T}_{003}, \mathrm{~T}_{012}, \mathrm{~T}_{013}, \mathrm{~T}_{022}, \mathrm{~T}_{023}, \mathrm{~T}_{111}$, $\mathrm{T}_{112}, \mathrm{~T}_{113}$, and $\mathrm{T}_{122}$ were provided. Accordingly, the rate coefficients for abstraction by $\dot{\mathrm{OH}}$ from $\mathrm{T}_{003}$ site in triptane is adopted from their calculations.

\subsubsection{Addition of alkyl $(R)$ and hydroperoxy alky ( $\dot{Q} O O H)$ radicals to $\mathrm{O}_{2}$}

Based on recent models $[12,17-20]$, the rate parameters calculated by Miyoshi [16] were adopted for alkyl radical addition to $\mathrm{O}_{2}$. However for the 2 nd addition to $\mathrm{O}_{2}\left(\mathrm{Q} \mathrm{OOH}+\mathrm{O}_{2}\right)$, the same rate parameters were used with A-factor halved following the findings of Goldsmith et al. [40].

2.2.4. Isomerization of peroxy alkyl radicals (ROO) into hydroperoxy alkyl radicals $(\dot{Q} \mathrm{OOH})$, isomerization of peroxy hydroperoxy alkyl radicals $(\mathrm{OOQOOH})$ and formation of ketohydroperoxides

Isomerization of ROO takes place through intramolecular hydrogen migration from alkyl group to peroxy group via cyclic transition state. According to the size of the transition state ring, this class is divided to 5,6 and 7 membered-ring transition states which are all included in the model. Villano et al. [14] provided rate rules 
for this class based on the ring size and nature of migrating hydrogen (primary, secondary and tertiary). These computed rate rules were used in our model.

Isomerization of $\mathrm{OOQOOH}$ followed by $\mathrm{O}-\mathrm{O}$ bond cleavage and $\dot{\mathrm{OH}}$ release is responsible for the low temperature chain branching. Sharma et al. [15] computed rate rules for isomerization of $\mathrm{OOQOOH}$ to ketohydroperoxides (KHP) at the CBS-QB3 and B3LYP/CBSB7 levels of theory with accurate treatment of hindered rotors. These rate rules were adopted in our study. The subsequent decomposition of KHP was assigned a rate of frequency (A) factor of $1.0 \times 10^{16} \mathrm{~s}^{-1}$ and activation energy of $41.6 \mathrm{kcal} \mathrm{mol}^{-1}$ [19].

\subsubsection{Concerted elimination}

Production of olefins and $\mathrm{HO}_{2}$ from peroxy alky radicals is responsible for reducing the fuel reactivity. Triptene is produced from the concerted elimination of tertiary (C7H15-BO2) and primary ( $\mathrm{C} 7 \mathrm{H} 15-\mathrm{CO} 2)$ triptyl peroxy radicals. The rate parameters for concerted elimination from $\mathrm{C} 7 \mathrm{H} 15-\mathrm{BO} 2$ are adopted from the work by Snitsiriwat and Bozzelli [41], following the iso-octane model [12]. The rate parameters computed by Villano et al. [14] for concerted elimination in highly branched alkanes are used for the concerted elimination from $\mathrm{C} 7 \mathrm{H} 15-\mathrm{CO} 2$. Please refer to the species dictionary in Supplementary material for the chemical structure of these species.

\subsubsection{Cyclic ether formation, and scission of $\dot{Q} \mathrm{OOH}$ species}

Hydroperoxy-alkyl radicals ( $\mathrm{Q} O \mathrm{OH})$ undergo addition to molecular oxygen, cyclic ether formation, and scission reactions. The reactions involving $\dot{\mathrm{OOOH}}$ radical addition to molecular oxygen have already been discussed above (Section 2.2.3). The scission reactions are divided into three classes; $\beta$-Q்OH $=$ olefin $+\mathrm{HO}_{2}$, $\gamma-\dot{Q} O O H=$ olefin + carbonyl $+\dot{\mathrm{O}} \mathrm{H}$ and $\delta$ - $\dot{Q} O O H=$ olefin $+\beta-\dot{\mathrm{QOOH}}$. The formation of $\mathrm{HO}_{2}$ and olefin is favored due to the weakness of the $\mathrm{C}-\mathrm{OOH}$ bond compared to a $\mathrm{C}-\mathrm{C}$ or $\mathrm{C}-\mathrm{H}$ bond. The rate parameters of $\beta$-Q்OH reaction class are based on the computational rate rules published by Villano et al. [13] while the other scissions are using the rate parameters recommended by Bugler et al. [18].

Another propagation reaction pathway for $\mathrm{QOOH}$ radicals is the formation of cyclic ethers $+\dot{\mathrm{O} H}$. These reactions were added with rate rules from [16] with doubled pre-exponent factor following our recent iso-octane model [12]. However, the formation of cyclic ether from $\mathrm{C} 7 \mathrm{H} 14-\mathrm{BAOOH}$ (please refer to the species dictionary for structure) was multiplied by two to better match the experimental data.

\subsubsection{Alternative isomerization}

In conventional models $[42,43]$, the only available pathway for peroxy hydroperoxy alkyl radicals $(\mathrm{OOQOOH})$ is the formation of ketohydroperoxides (KHP) assuming that the $\mathrm{H}$-atom at the $\mathrm{C}-\mathrm{OOH}$ site is the easiest to abstract due to the weak $\mathrm{C}-\mathrm{H}$ bond. However, recent models [12,17-20] incorporated isomerization from other carbon sites in OOQOOH to produce dihydroperoxy alkyl radical $\left(\mathrm{P}(\mathrm{OOH})_{2}\right)$. The formed $\mathrm{P}(\mathrm{OOH})_{2}$ undergoes $\beta$ - scission and formation of cyclic ethers. Accordingly, this pathway is included in our triptane model. An example of this pathway and the conventional one is shown in Fig. 5. It is worth-noting that another possible pathway for $\mathrm{OOQOOH}$ is concerted $\mathrm{HO}_{2}$ elimination. This pathway was implemented in the iso-octane model by Atef et al. [12], however it was found unimportant. Thus, concerted $\mathrm{HO}_{2}$ elimination of OOQOOH was not implemented in the triptane model to reduce the computational cost and to be comparable with other models for heptane isomers.

Similar to our approach in the iso-octane model [12], we used analogies to assign rate coefficients for the alternative isomerization and subsequent reactions. For alternative isomerization and $\beta$ - scission of $\mathrm{P}(\mathrm{OOH})_{2}$ species, we used Villano et al.'s [13] rate

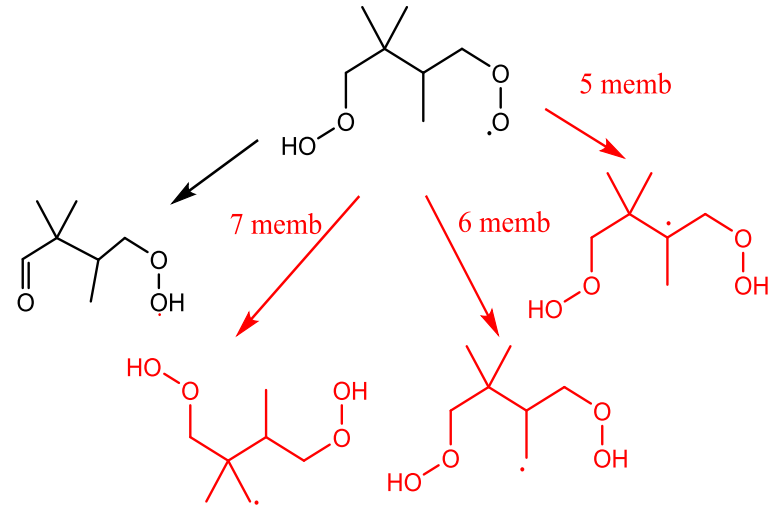

Fig. 5. Conventional (black) and alternative (red) isomerization for one of the species. (For interpretation of the references to colour in this figure legend, the reader is referred to the web version of this article.)

coefficients for ROÖ/Q்OH isomerization and $\beta$-scission of $\dot{\mathrm{Q} O O H}$, respectively. Meanwhile, Miyoshi's [16] rate coefficients of cyclic ether formation were used for the formation of hydroperoxy cyclic ethers.

\section{Experimental}

\subsection{Rapid compression machine (RCM)}

Low-temperature ignition delay measurements of the 2,2,3 trimethylbutane were carried out at 20 and 40 bar and at equivalence ratios of 1 and 0.5 in the KAUST RCM, which has similar design to the National University of Ireland (NUI) Galway RCM [44] with dual-opposed piston arrangement. The dual piston design provides better mechanical balance with lower vibration levels and faster compressions compared to the single piston one. The combustion chamber diameter of the KAUST RCM is $50.8 \mathrm{~mm}$ and the total piston stroke length is $238 \mathrm{~mm}$. The variable compression ratio was set to be 13:1 for these experiments. Two mixing vessels with magnetic stirrers were utilized to prepare homogenous fuel mixtures, one for the reactive mixtures and the other one for non-reactive (without oxygen) mixtures. The compression time is $16 \mathrm{~ms}$ with the highest increase in pressure occurring in the last $3 \mathrm{~ms}$ of the compression stroke. Pistons are driven pneumatically and arrested at the end of compression by the hydraulic locking system. The combustion chamber and piston sleeves are heated using insulated heating jackets as well as tapes. Pressure profiles are recorded by a Kistler 6045A pressure transducer which is installed on the combustion chamber wall. Creviced piston head designs are applied in order to achieve homogenous compression by suppressing the vortex roll-up [45].

The definition of the ignition delay time is the interval from the peak pressure at the end of compression to the maximum pressure rise due to the ignition process. The compressed gas temperature $\left(T_{c}\right)$ is calculated from the adiabatic compression/expansion equation;

$\ln \left(\frac{P_{c}}{P_{i}}\right)=\int_{T_{i}}^{T_{c}} \frac{\gamma}{\gamma-1} \frac{d T}{T}$

where $T_{i}$ and $P_{i}$ are the initial temperature and pressure of the mixture, whereas $T_{c}$ and $P_{c}$ are the compressed gas temperature and pressure respectively, and $\gamma$ is the ratio of specific heats.

The RCM experiments for 2,2,3 trimethylbutane were carried out over a temperature range of $620-1015 \mathrm{~K}$. Different temperatures at the end of compression are obtained by either varying initial temperature or diluent concentration/diluent gas type. 

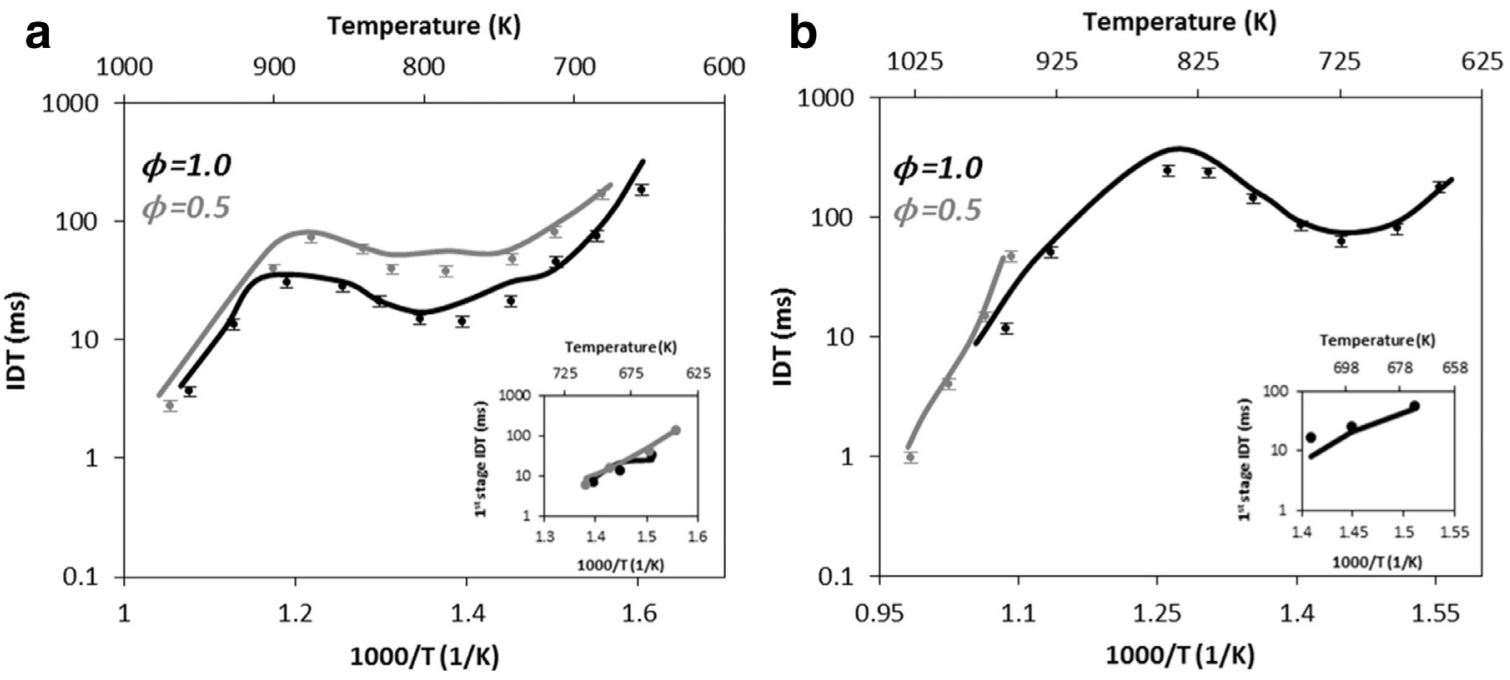

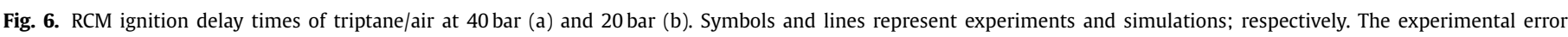
bars are shown on the figure. The Insets represent the 1st stage IDT.

In general, the uncertainty in measured ignition delay times is estimated to be less than $10 \%[46,47]$.

\subsection{Shock tube (ST)}

High-temperature ignition delay times of triptane in air mixtures were measured behind reflected shock waves using the lowpressure shock tube (LPST) facility at KAUST. The stainless steel tube has an inner diameter of $14.2 \mathrm{~cm}$ and consists of a $9 \mathrm{~m}$ driver section and a $9 \mathrm{~m}$ driven section, where the two sections are separated by a polycarbonate diaphragm. The driver section is divided into four compartments so the total length can be varied depending on the required test times. Long test times were achieved by using the full length of the driver section and employing driver gas tailoring. Incident shock velocity was measured using five equally spaced piezoelectric PCB pressure transducers situated in the last $1.5 \mathrm{~m}$ of the driven section. Reflected shock temperatures and pressures were determined from the measured incident shock speed and normal shock relations [48]. Pressure traces were recorded by a Kistler 603B piezoelectric pressure transducer. Ignition delay time was defined as the time between the arrival of the reflected shock wave and an extrapolated tangent line to the point of maximum rate-of-change of pressure. Uncertainties in the calculated pressure and temperature are approximately $\pm 0.7 \%$ and $\pm 1 \%$, respectively, mainly due to the uncertainty in the measured shock velocity $( \pm 0.2 \%)$ [48]. Uncertainty in the measured ignition delay times is estimated to be less than $20 \%$. A magneticallystirred mixing tank and a well-furnished mixing manifold were used to prepare gaseous mixtures. 2,2,3 - Trimethylbutane (>99\%) from ChemSampCo, oxygen and nitrogen (99.999\%) from Air Liquide were used.

\subsection{Jet stirred reactor (JSR)}

The oxidation experiment of triptane was performed at atmospheric pressure in a jet-stirred reactor (JSR) at KAUST. The experimental setup was previously validated with n-heptane oxidation and the results reached good agreement with other groups [49,50]. A $76 \mathrm{~cm}^{3}$ spherical quartz reactor consists of four opposing nozzles $(0.3 \mathrm{~mm}$ diameter) to attain the homogeneity of species and temperature distribution. Triptane in liquid phase was stored in a 10-ml syringe (SGE Analytical), pumped and vaporized through a home-made vaporizer at $423 \mathrm{~K}$. The upstream of the reactor was preheated to the reaction temperature zone (700-1050 K) to avoid gradient distribution of the reactor temperature. The mixture of $\mathrm{N}_{2}$ and fuel was introduced into the reactor through a quartz tube with inner diameter of $1 \mathrm{~mm}$ while the mixture of $\mathrm{N}_{2}$ and $\mathrm{O}_{2}$ was introduced into the reactor through an outer quartz channel. Then the two flows were mixed at the inlet of the reactor, which prevents reactions before premixing in the spherical reactor. The fuel concentration was fixed at $5000 \mathrm{ppm}$ in all conditions. Low fuel concentration was necessary to avoid heat release inside the reactor. The MKS mass flow controllers were used to regulate the flow rates of $\mathrm{N}_{2}$ and $\mathrm{O}_{2}$ under different temperatures to maintain the residence time of $2 \mathrm{~s}$.

At the downstream, a sonic probe, attached to a vacuum suction pump, was installed to collect sample species at low pressure in order to freeze the reactions. A K-type thermocouple was inserted, next to the sonic probe, for monitoring the temperature inside the JSR. The thermocouple was placed in a quartz tube to prevent catalyzing reactions. Online analysis of the collected samples was carried out by connecting the transfer line to two gas chromatography (GC) systems and all end-products were remained at $423 \mathrm{~K}$. One is refinery gas analyzer (RGA) which is a specially designed GC apparatus equipped with a flame ionization detector (FID) and two thermal conductivity detectors (TCD). FID is used to quantify light hydrocarbons from methane to $\mathrm{C} 5$ hydrocarbons and TCDs are to detect $\mathrm{CO}_{2}, \mathrm{CO}, \mathrm{H}_{2}$ and $\mathrm{O}_{2}$. The uncertainty in the measurement of fuel $/ \mathrm{O}_{2}$ concentration and intermediates is $10 \%$ and $20 \%$, respectively. Another GC system (Agilent 7890B) was equipped with DB1 column and FID to detect triptane. Various results under temperature from 700 to $1050 \mathrm{~K}$ and equivalence ratios $0.5,1,2$ were acquired.

\section{Results and discussions}

The new developed model was used to simulated the ignition delay time (IDT) data measured in the RCM using CHEMKIN-PRO [51]. Variable volume simulations were conducted in order to account for the heat loss in the post-compression time of the RCM experiments. Non-reactive volume profiles, mixture compositions and experimental conditions are provided in the Supplementary material.

Figure 6 shows the experimental and simulation IDT results at 40 bar and 20 bar for two equivalence ratios; 0.5 and 1 . The 1st stage IDT is also presented in the figure. Figure 6a shows 

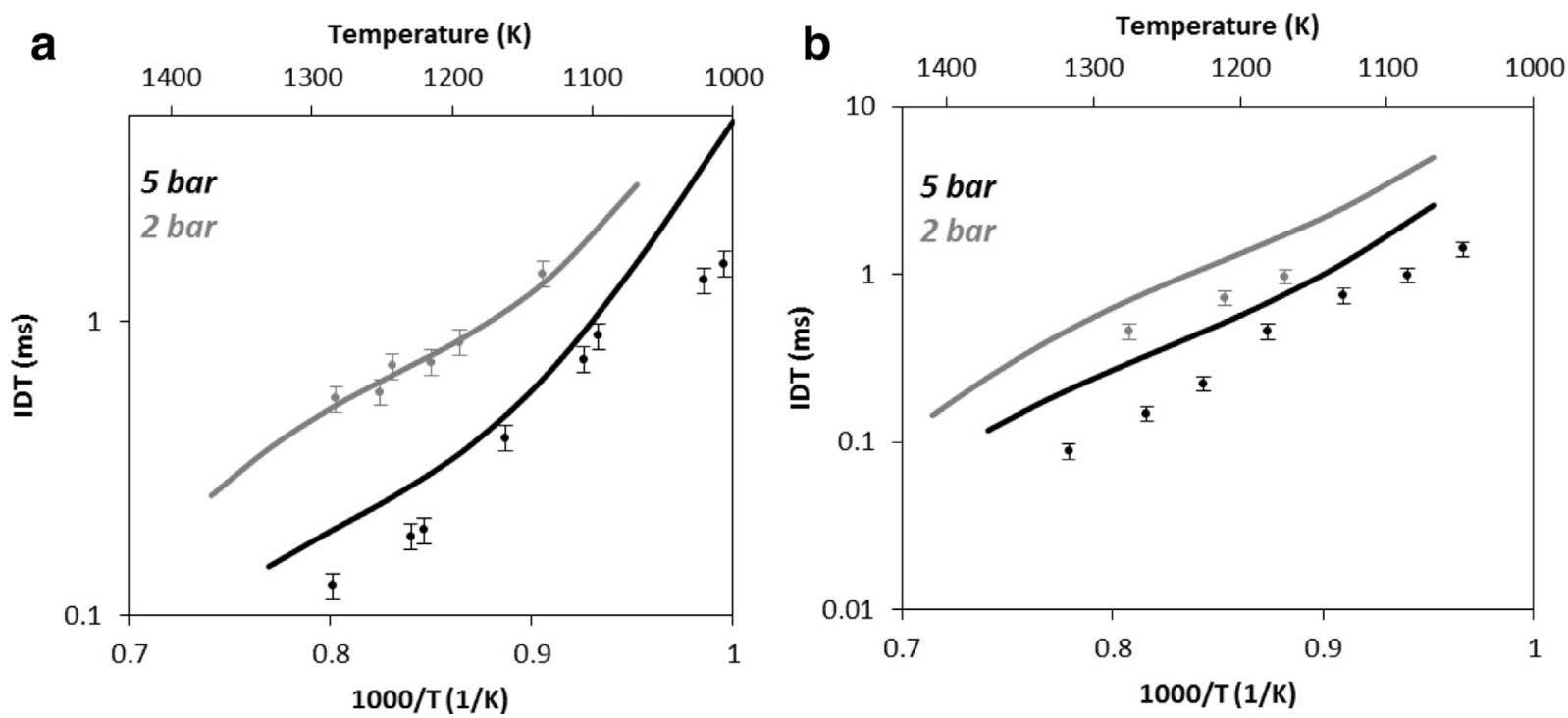

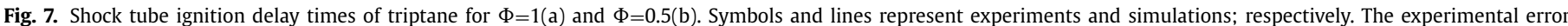
bars are shown on the figure.
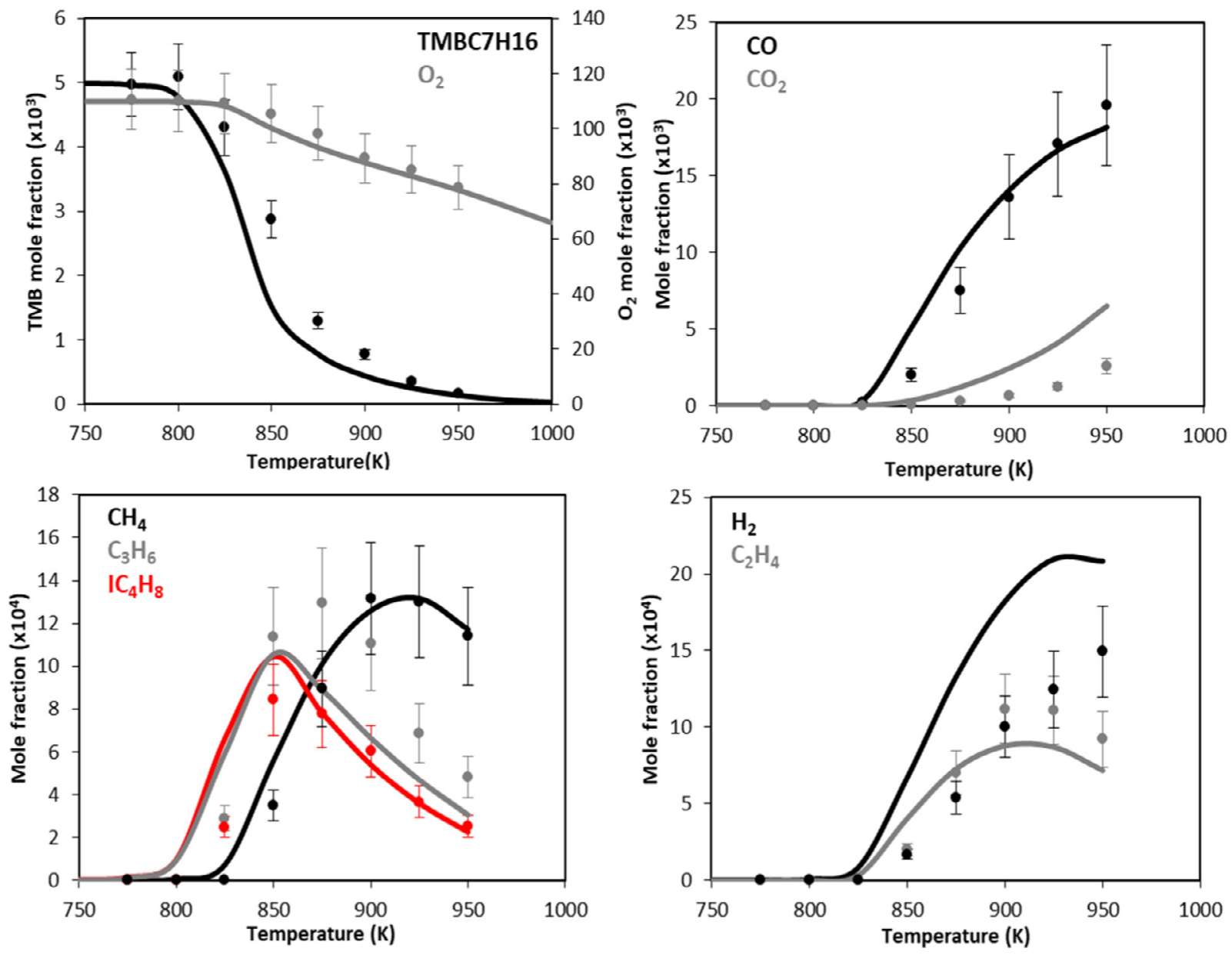

Fig. 8. JSR speciation data for $0.5 \%$ triptane at 0.5 equivalence ratio. Symbols and lines represent experiments and simulations; respectively.

IDT data across a temperature range $600-1000 \mathrm{~K}$, which covers the low- and high-temperature regimes of triptane. As the temperature increases, the IDT first decreases then slightly increases and finally decreases again. This corresponds to, low-temperature chemistry, negative temperature coefficient (NTC) region and high-temperature chemistry; respectively. The figure demonstrates a less pronounced NTC behavior associated with triptane combustion, which is attributed to the less available sites for isomerization in the highly branched alkane. Comparing both equivalence ratios clearly indicates that the higher equivalence ratio shortens the IDT at low-temperature and NTC regimes wherein chain branching occurs through production of KHP which depends on fuel 

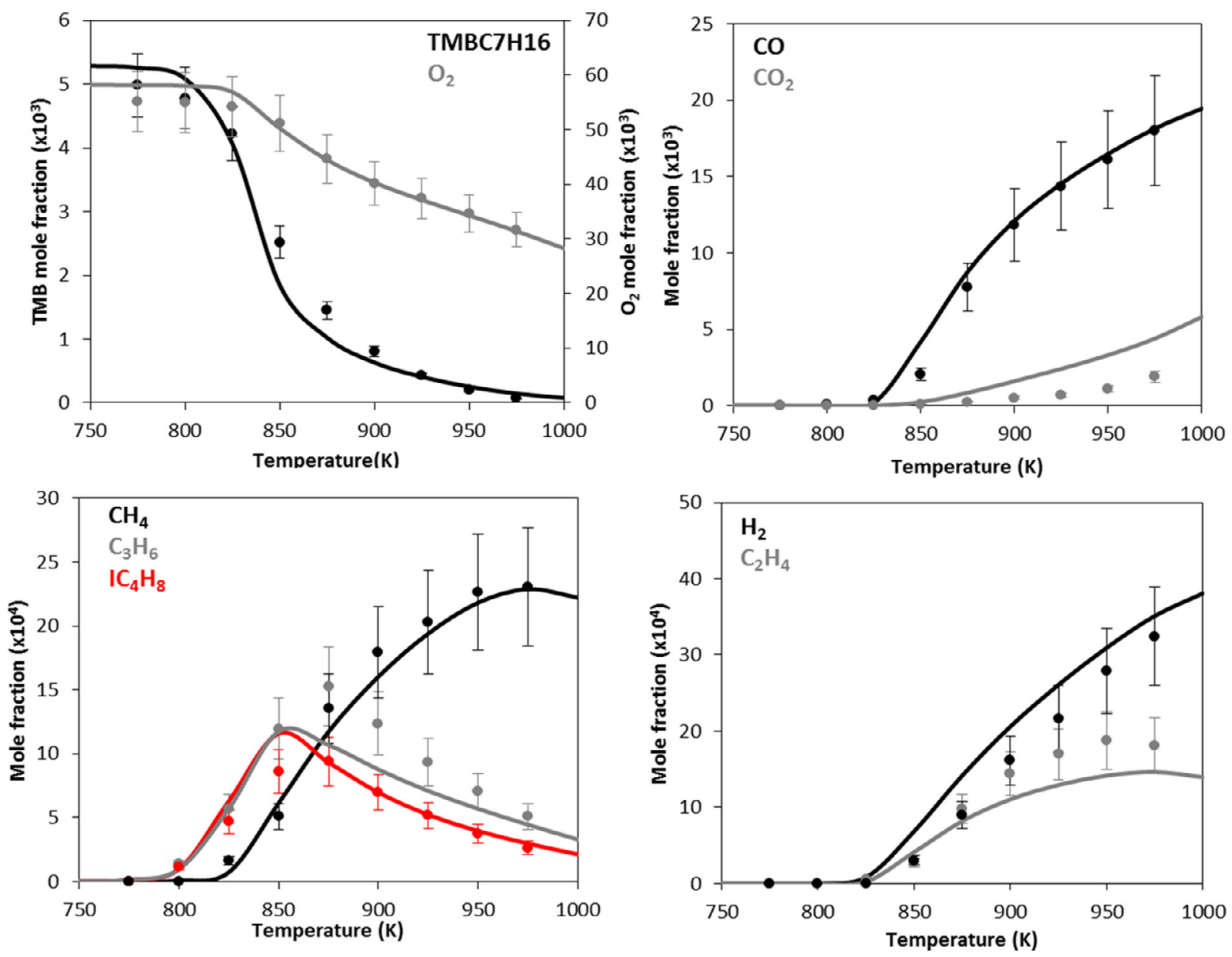

Fig. 9. JSR speciation data for $0.5 \%$ triptane at equivalence ratio of 1 . Symbols and lines represent experiments and simulations; respectively. The error bars are shown.

concentration [12,42]. However, the difference between the IDT of both mixtures (stoichiometric and lean) becomes negligible at high temperatures where chain branching occurs through $\mathrm{H}+\mathrm{O}_{2}=\mathrm{O}+\mathrm{OH}$. Similar behavior is seen in Fig. $6 \mathrm{~b}$ for 20 bar data even though the low reactivity of triptane prevented measuring IDT at temperatures lower than $900 \mathrm{~K}$. Generally, simulation results are comparable with the experimental data.

Figure 7 presents the experimental and simulated ignition delay times for triptane conducted at low pressures of 2 and 5 bars and high temperatures of 1000 to $1400 \mathrm{~K}$. The model is comparable to the experimental measurements at $\Phi=1$, however less reactivity exhibited by the model can be seen at $\Phi=0.5$. This discrepancy is analyzed at the end of this section.

The JSR experiments were simulated using the perfectly stirred reactor module in CHEMKIN-PRO [51]. Figures 8-10 show experimental and simulated JSR speciation data for $0.5 \%$ triptane in $\mathrm{N}_{2} / \mathrm{O}_{2}$ mixture at $1 \mathrm{~atm}, 2 \mathrm{~s}$ residence time and three equivalence ratios of $0.5,1$ and 2 , respectively. The considered temperature range is $750-1000 \mathrm{~K}$ which corresponds to NTC and high temperature regions.

The fuel (TMBC7H16) and $\mathrm{O}_{2}$ consumptions are well reproduced by the model, except for $\Phi=2$ where $\mathrm{O}_{2}$ is lower in the simulations. Further analysis of this discrepancy is presented at the end of this section. The simulation profiles for CO are in good agreement with experimental data and within the uncertainty limit; however, the model predicts higher $\mathrm{CO}_{2}$ concentrations for the three equivalence ratios. iso-Butene $\left(\mathrm{IC}_{4} \mathrm{H}_{8}\right)$ is well reproduced by the model, as seen in the figures, and this might be attributed to the improved iso-butene chemistry in Aramco 2 [21] base chemistry. Methane $\left(\mathrm{CH}_{4}\right)$ profiles are well captured by the model considering the experimental uncertainty, albeit propene $\left(\mathrm{C}_{3} \mathrm{H}_{6}\right)$ is slightly under-predicted at the 3 equivalence ratios. Hydrogen $\left(\mathrm{H}_{2}\right)$ is reproduced at stoichiometric and rich conditions $(\Phi=1$ and 2$)$, nonetheless it is over-predicted at $\Phi=0.5$. Finally, simulated ethylene $\left(\mathrm{C}_{2} \mathrm{H}_{4}\right)$ concentrations are lower than experiments at the 3 equivalence ratios.

The newly developed model generally well reproduced the wide range of experimental data. Nonetheless, some discrepancies can be seen in the JSR and ST data. Specifically, the under-prediction of $\mathrm{O}_{2}$ mole fraction at $\Phi=2$ in JSR simulations and the low reactivity of the model at $\Phi=0.5$ against the low pressure ST data. In order to assess this discrepancy, sensitivity analyses were conducted using CHEMKIN-PRO according to this formula;

$S_{l i}=\frac{\partial \varphi_{l}}{\partial \alpha_{i}}$

where $S_{l i}$ is the normalized sensitivity coefficient of quantity 1 (temperature or $\mathrm{O}_{2}$ mass fraction) with respect to reaction $\mathrm{i}, \varphi_{l}$ is the dependent variable vector of $1, \alpha_{i}$ is the rate constant of reaction i.

The results are shown in Fig. 11.

Figure 11(a) shows the $\mathrm{O}_{2}$ sensitivity analysis at $\Phi=2$ and $875 \mathrm{~K}$. A negative sensitivity coefficient means decreasing the consumption of $\mathrm{O}_{2}$ and vice versa. Figs. 11(b) and (c) show the temperature sensitivity analyses for IDT of triptane in air at $1170 \mathrm{~K}$ and 5 bar for $\Phi=1$ and 0.5 ; respectively. Positive and negative temperature sensitivities indicate increasing and decreasing the reactivity of the model, respectively. It can be clearly seen that the reactions 

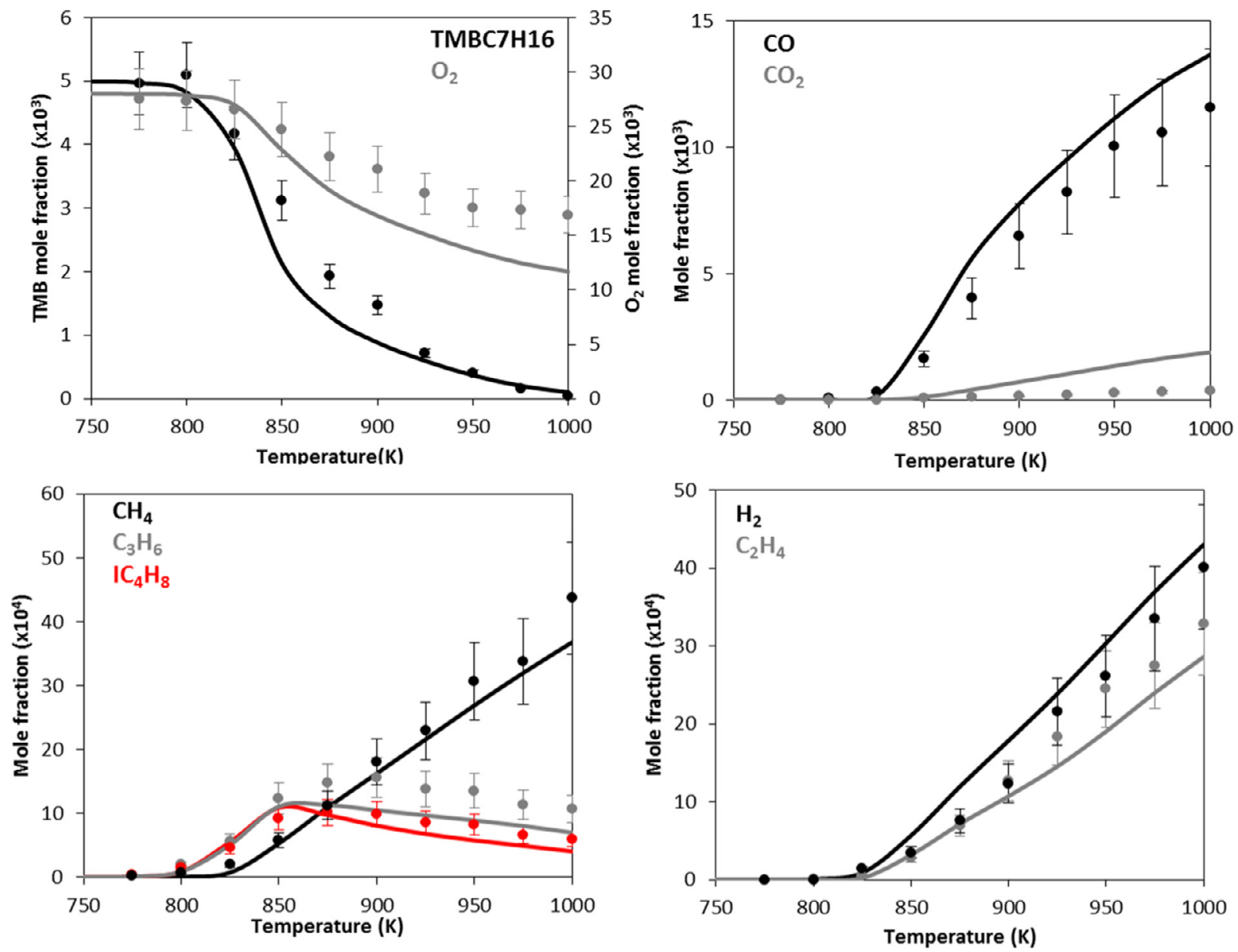

Fig. 10. JSR speciation data for $0.5 \%$ triptane at equivalence ratio of 2 . Symbols and lines represent experiments and simulations; respectively. The error bars are shown.

responsible for the reactivity (Figs. (b) and (c)) are mainly base chemistry reactions, which is expected at such high temperature $(1170 \mathrm{~K})$. Accordingly, the low model reactivity at $\Phi=0.5$ could not be fixed without changing the base chemistry. It is worth mentioning that, using Aramco 3.0 [52] base chemistry couldn't fix the reactivity. More experimental data for triptane at high temperatures are required to elucidate this discrepancy.

Figure 11(a) and (b) shows that the unimolecular decomposition of triptane across the secondary-tertiary bond (TMBC7H16 $<=>$ TC4H9+IC3H7) increases reactivity for IDT at 5 bar and $\Phi=1$ and also increases $\mathrm{O}_{2}$ consumption in the JSR simulations at $\Phi=2$. Considering the good prediction of the model against the experimental IDT, tuning any of these rates to better predict the $\mathrm{O}_{2}$ JSR profile at $\Phi=2$ will result in mismatching the ST data.

The sensitivity analyses show the importance of the reaction TMBC7H16 $<=>$ TC4H9+IC3H7. The rate adopted for this reaction was based on analogy with iso-octane model (refer to Section 2.2.1). Computing the rate parameters for this reaction using high level of computational theories may improve the model prediction at high temperatures.

\section{Sensitivity analysis}

To understand the relative importance of different reactions on triptane ignition, brute force sensitivity was conducted. The analysis was conducted for stoichiometric triptane/air mixture at 40 bar and three temperatures, $650 \mathrm{~K}, 740 \mathrm{~K}$ and $900 \mathrm{~K}$, which correspond to low temperature, NTC and high temperature regions. The results are presented in Fig. 12.
OH-sensitivity analyses were first conducted using CHEMKINPRO [51] at each condition to determine the reactions that should be considered for brute force sensitivity analysis. Then brute force sensitivity was conducted considering these reactions determined by the $\mathrm{OH}$-sensitivity. The sensitivity coefficient of every reaction, at each temperature condition, was then calculated as:

$\sigma=\frac{\log \left(\frac{\tau_{2}}{\tau_{0.5}}\right)}{\log \left(\frac{2}{0.5}\right)}$

where $\tau_{2}$ and $\tau_{0.5}$ are the IDT calculated with rate constant doubled and halved, respectively. A positive sensitivity coefficient $(\sigma)$ indicates that the specified reaction increases the simulated ignition delay time, and thus, decreases reactivity, and vice versa.

At $650 \mathrm{~K}$ and $740 \mathrm{~K}$, the most negatively sensitive reaction (i.e. increases reactivity) is the $\mathrm{H}$-abstraction by $\mathrm{OH}$ to produce $\mathrm{C} 7 \mathrm{H} 15-$ A $(\mathrm{TMBC} 7 \mathrm{H} 16+\mathrm{OH}=\mathrm{C} 7 \mathrm{H} 15-\mathrm{A}+\mathrm{H} 2 \mathrm{O})$. This radical has the highest rate of production (seen in the next section), due to the degeneracy effect (i.e. 9 hydrogens available for abstraction). In addition, this radical experiences a second addition to molecular oxygen, increasing the reactivity. On the other hand, the formation of the tertiary triptyl radical (C7H15-B) shows the highest positive sensitivity (decreases reactivity) where most of this radical forms alkenes, instead of hydroperoxyalkyl radicals $(\mathrm{QOOH})$ via addition to molecular oxygen and intramolecular $\mathrm{H}$-atom migration. In the case of $650 \mathrm{~K}$ and $740 \mathrm{~K}$, the concerted elimination of the tertiary triptyl radical (formation of olefin) is the second and third most positive reaction $(\mathrm{C} 7 \mathrm{H} 15-\mathrm{BO} 2<=>\mathrm{TMBC} 7 \mathrm{H} 14+\mathrm{HO} 2)$, respectively. Isomerization of $\mathrm{C} 7 \mathrm{H} 15-\mathrm{BO} 2$ competes with the formation of olefins; 


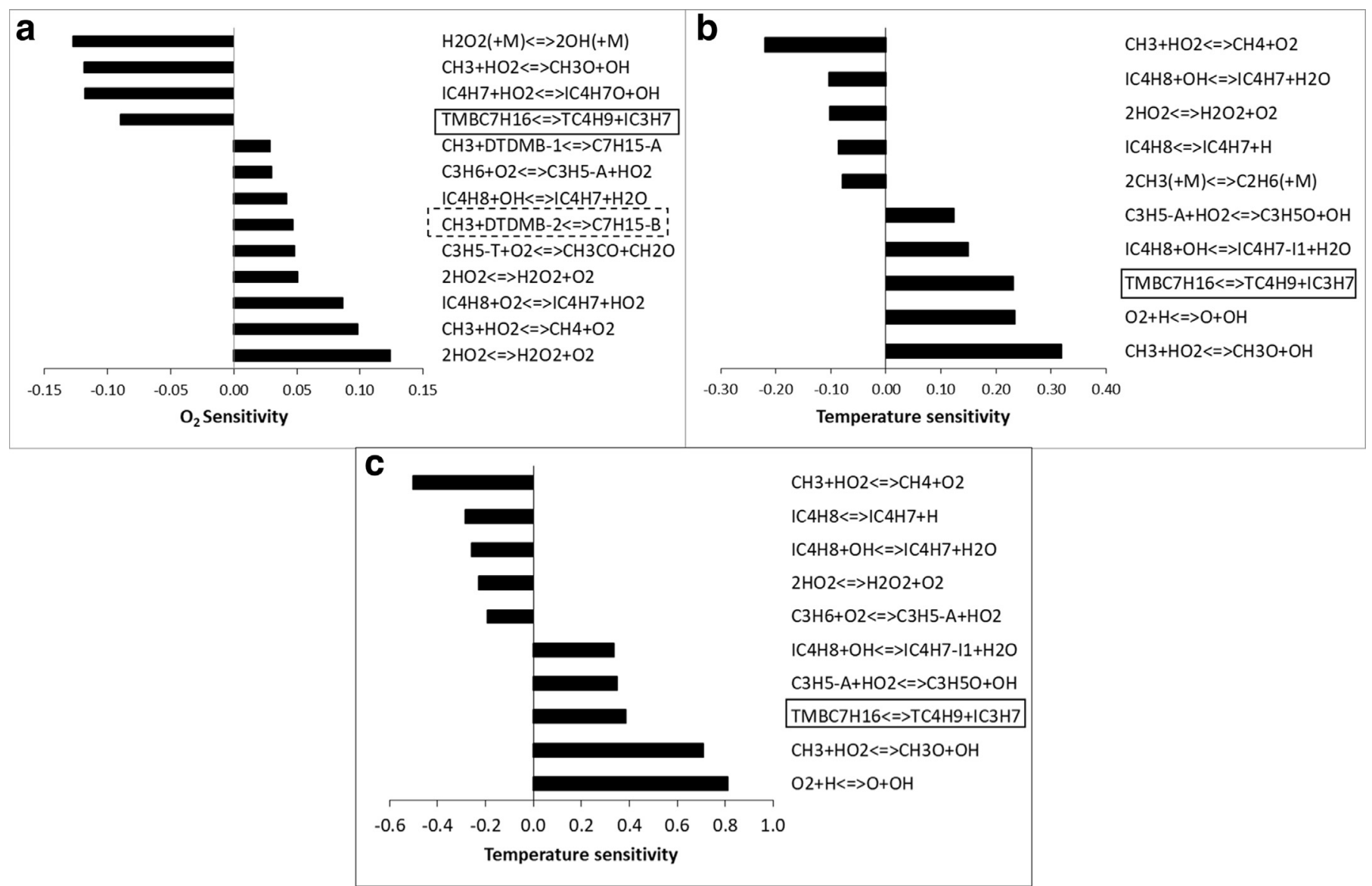

Fig. 11. (a) $\mathrm{O}_{2}$ sensitivity analysis for JSR at $\Phi=2$ and $875 \mathrm{~K}$, (b) and (c) temperature sensitivity analyses for IDT at 5 bar, $1170 \mathrm{~K}$ and $\Phi=1$ and 0.5 ; respectively.

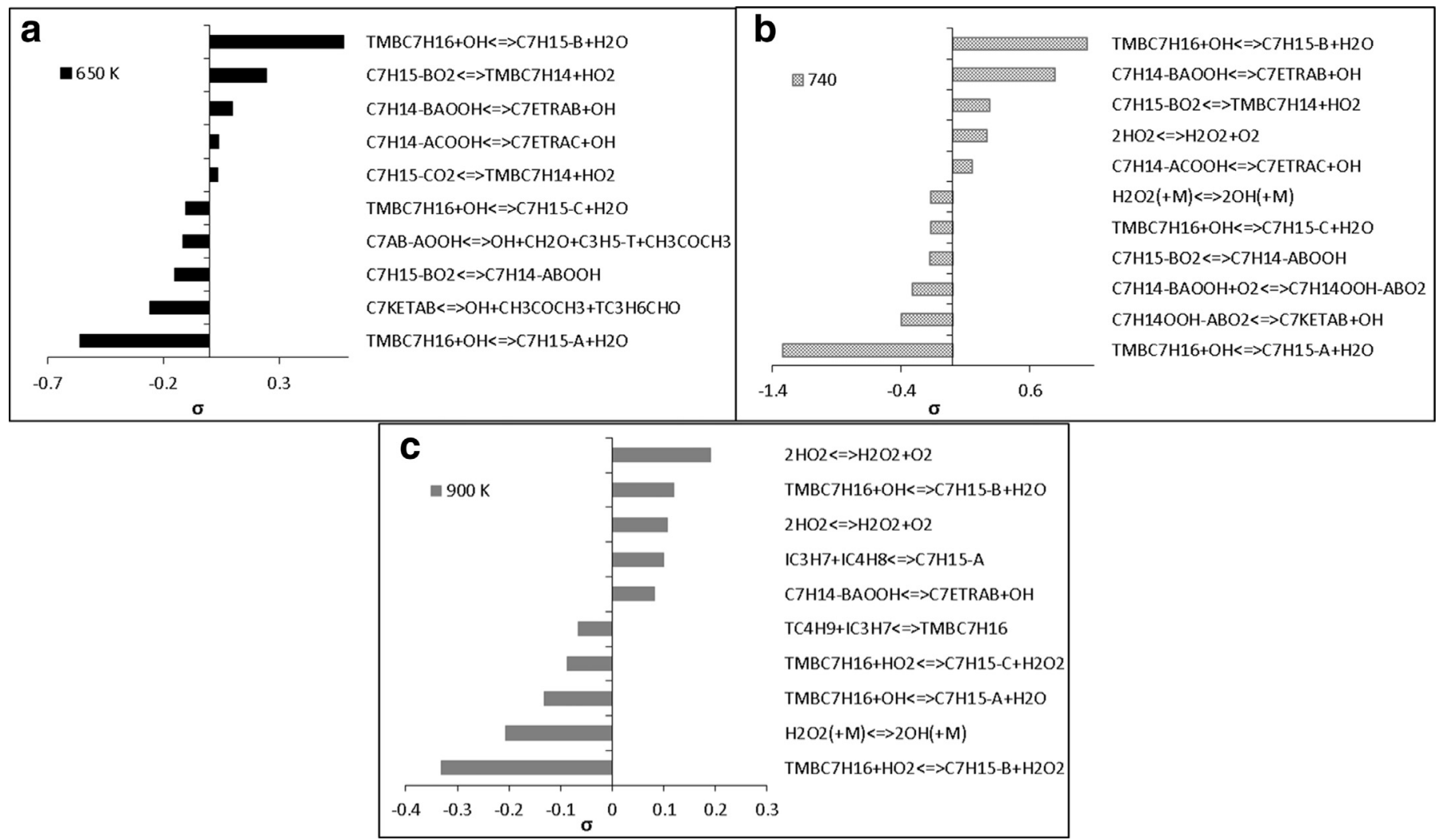

Fig. 12. Brute force sensitivity analyses for ignition delay of stoichiometric triptane/air mixtures at $40 \mathrm{~atm}$ and different temperatures. (Refer to Supplementary material for species dictionary.). 


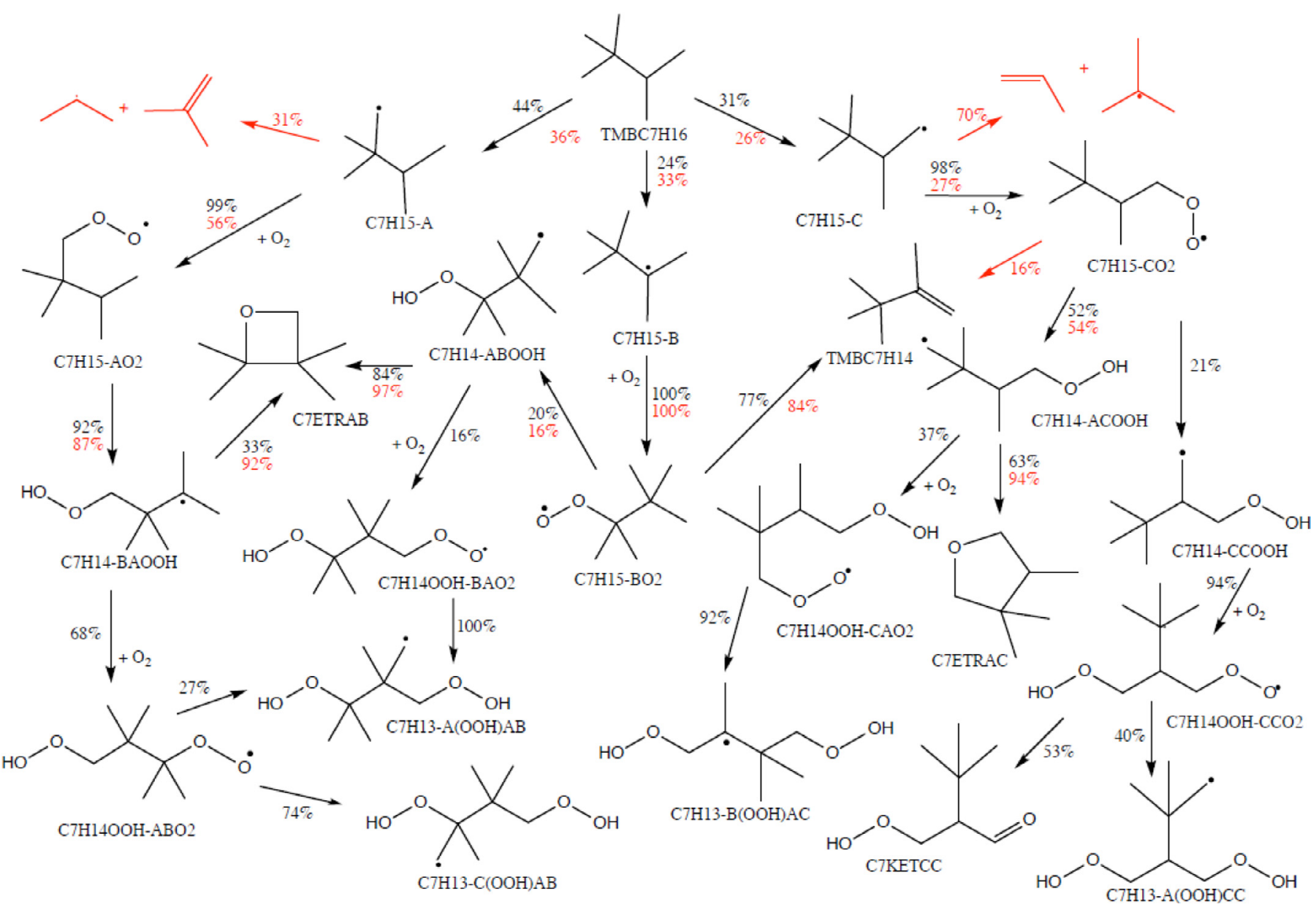

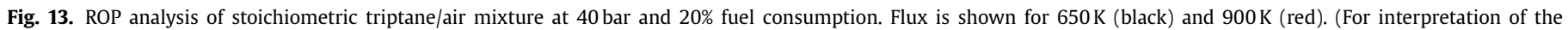
references to colour in this figure legend, the reader is referred to the web version of this article.)

consequently, $\mathrm{C} 7 \mathrm{H} 15-\mathrm{BO} 2<=>\mathrm{C} 7 \mathrm{H} 14-\mathrm{ABOOH}$ shows negative sensitivity, as demonstrated in Fig. 12. Analogous to $\mathrm{C} 7 \mathrm{H} 15-\mathrm{BO} 2$, the concerted elimination of $\mathrm{C} 7 \mathrm{H} 15-\mathrm{CO} 2$ also shows positive sensitivity (C7H15-CO2 <=> TMBC7H14+HO2).

Like C7H15-A, the $\mathrm{H}$-abstraction to produce $\mathrm{C} 7 \mathrm{H} 15-\mathrm{C}$ also shows negative sensitivity at both temperatures. The formation of cyclic ethers (C7H14-BAOOH $<=>$ C7ETRAB $+\mathrm{OH}$ and $\mathrm{C} 7 \mathrm{H} 14-$ $\mathrm{ACOOH}<=>\mathrm{C}$ ETRAC $+\mathrm{OH}$ ) shows positive sensitivity at both temperatures because it competes with the second addition to molecular oxygen and hinders the chain branching pathway.

The decomposition of $\mathrm{KHP}(\mathrm{C} 7 \mathrm{KETAB}<=>\mathrm{OH}+\mathrm{CH} 3 \mathrm{COCH} 3+$ $\mathrm{TC} 3 \mathrm{H} 6 \mathrm{CHO}$ ) presents the second most negative reaction at $650 \mathrm{~K}$. It is known that the main pathway at low temperature is the production of KHP, so its decomposition is crucial for low temperature reactivity. Moreover, the decomposition of hydroperoxy cyclic ether ( $\mathrm{C} 7 \mathrm{AB}-\mathrm{AOOH}<=>\mathrm{OH}+\mathrm{CH} 2 \mathrm{O}+\mathrm{C} 3 \mathrm{H} 5-\mathrm{T}+\mathrm{CH} 3 \mathrm{COCH} 3)$ also shows negative sensitivity, emphasizing the importance of the alternative isomerization pathway at low temperature. It is worth mentioning that, although the production of cyclic ethers inhibits reactivity, the formation of hydroperoxy cyclic ethers increases reactivity as it leads to chain branching pathway. This is due to the formation of one $\dot{\mathrm{OH}}$ radical during their formation and another one during their decomposition.

The formation of KHP (C7H14OOH-ABO2 $<=>$ C7KETAB $+\mathrm{OH})$ and the second addition to molecular oxygen (C7H14$\mathrm{BAOOH}+\mathrm{O} 2<=>\mathrm{C} 7 \mathrm{H} 14 \mathrm{OOH}-\mathrm{ABO} 2)$ show negative sensitivity at $740 \mathrm{~K}$. It is worth noting that NTC is caused by the competition between chain branching pathways through a second addition to

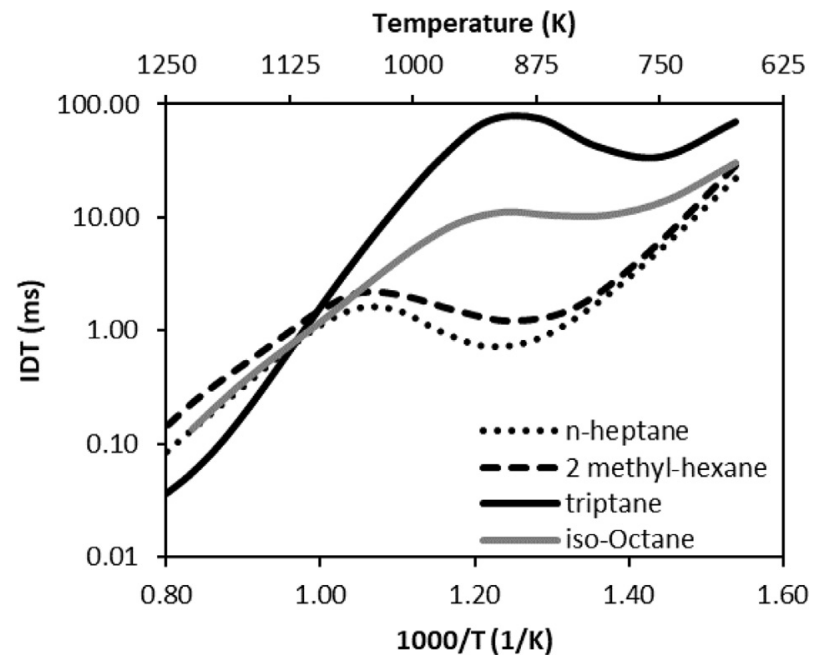

Fig. 14. Computed IDTs for heptane isomers and iso-octane at 25 bar and $\Phi=1$.

molecular oxygen, followed by formation of KHP and the chain propagation through the formation of cyclic ethers. As previously discussed, the low temperature chemistry of triptane is less pronounced because it is highly branched, as a result some of the high temperature chemistry shows at $740 \mathrm{~K}$. Figure $12 \mathrm{~b}$ shows that $\mathrm{H} 2 \mathrm{O} 2(+\mathrm{M})<=>2 \mathrm{OH}(+\mathrm{M})$ increases reactivity while $2 \mathrm{HO} 2<=>\mathrm{H} 2 \mathrm{O} 2+\mathrm{O} 2$ decreases reactivity at $740 \mathrm{~K}$. 


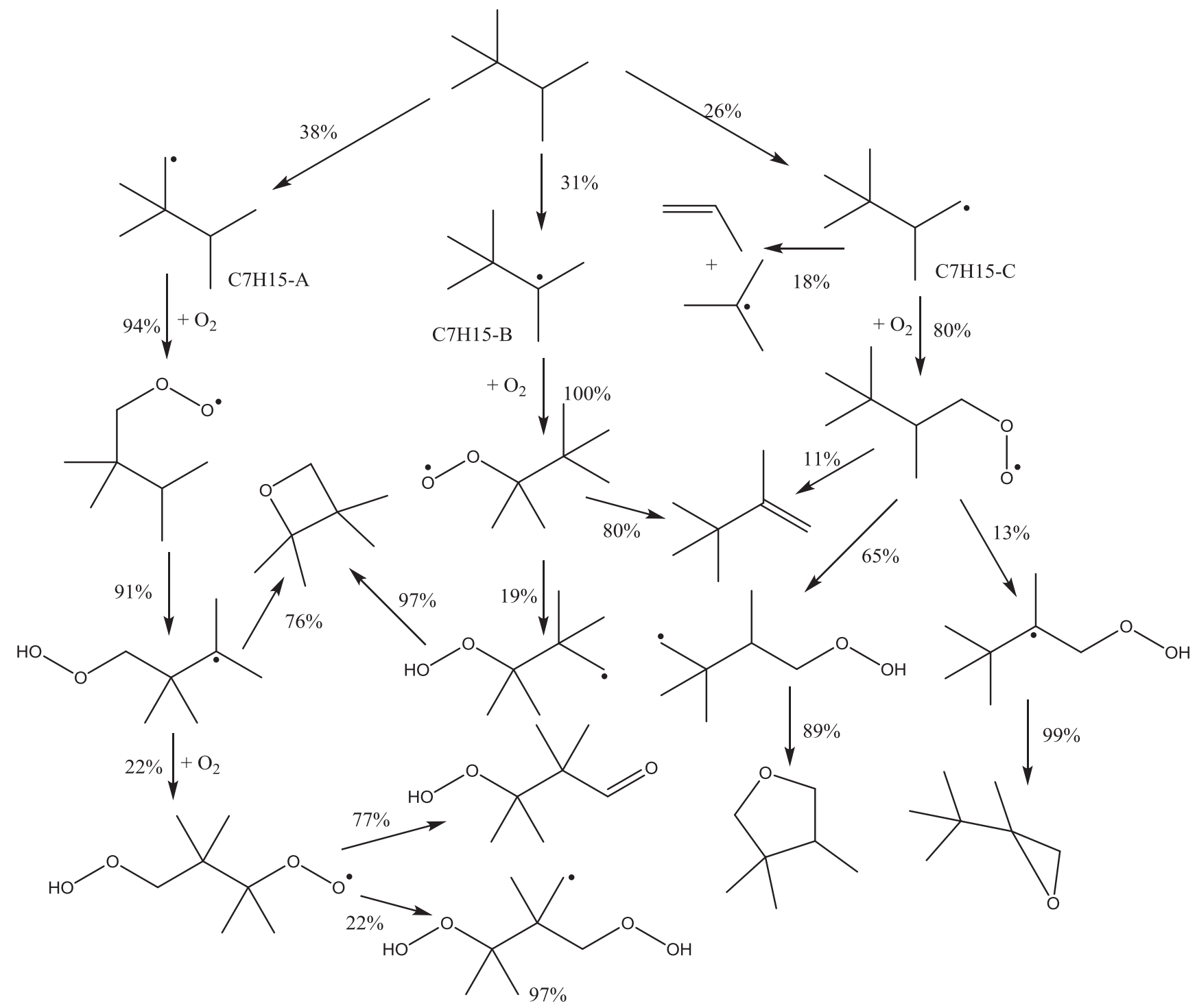

Fig. 15. ROP of stoichiometric triptane/air mixture at 25 bar and $750 \mathrm{~K}$.

The importance of these high temperature reactions increases at high temperatures, as seen in Fig. 12c, demonstrating that $\mathrm{H} 2 \mathrm{O} 2(+\mathrm{M})<=>2 \mathrm{OH}(+\mathrm{M})$ is the second most negatively sensitive reaction while $2 \mathrm{HO} 2<=>\mathrm{H} 2 \mathrm{O} 2+\mathrm{O} 2$ and its duplicate are the first and third most positively sensitive reactions. The H-abstraction to form C7H15-A and C7H15-B and C7H14$\mathrm{BAOOH}<=>\mathrm{C} 7 \mathrm{ETRAB}+\mathrm{OH}$ display the same trend seen in Fig. 12a and $\mathrm{b}$. Interestingly, $\mathrm{H}$-abstraction reactions by $\mathrm{HO}_{2}$ shows negative sensitivity in Fig. 12c (TMBC7H16 + HO2 $<=>$ C7H15- $B+\mathrm{H} 2 \mathrm{O} 2$ and $\mathrm{TMBC} 7 \mathrm{H} 16+\mathrm{HO} 2<=>\mathrm{C} 7 \mathrm{H} 15-\mathrm{C}+\mathrm{H} 2 \mathrm{O} 2)$, where the high activation barrier of these reactions is crossed at such elevated temperatures. Although the production of $\mathrm{C} 7 \mathrm{H} 15-\mathrm{B}$ radical through $\mathrm{H}$-abstraction by $\mathrm{OH}$ shows positive sensitivity (TMBC7H16 $+\mathrm{OH}$ $<=>\mathrm{C} 7 \mathrm{H} 15-\mathrm{A}+\mathrm{H} 2 \mathrm{O}$ ), the $\mathrm{H}$-abstraction by $\mathrm{HO}_{2}$ displays negative sensitivity where it is accompanied by the production of $\mathrm{H}_{2} \mathrm{O}_{2}$, which is responsible for the production of $\mathrm{OH}$ and the increasing reactivity at this temperature. In addition, the beta-scission of C7H15-A (IC3H7 + IC4H8 $<=>$ C7H15-A) shows positive sensitivity in Fig. 12c, where it begins to compete with the addition to molecular oxygen at high temperatures. Even though the unimolecular decomposition of triptane is considered to be a sensitive reaction in the figure (TC4H9+ IC3H7 $<=>$ TMBC7H16), further ROP analysis showed that only $0.34 \%$ of triptane goes through this pathway. The range of the sensitivity coefficient $(\sigma)$ axis should be considered when comparing reactions at different temperatures.

\section{Rate of production analysis}

The rate of production (ROP) analysis was conducted at 40 bar for stoichiometric triptane/air mixture to better understand the mechanism of triptane oxidation. The analysis was carried out at $20 \%$ of fuel consumption, and two temperatures were considered, $650 \mathrm{~K}$ and $900 \mathrm{~K}$, which corresponds to low and high temperature regions, respectively. The results are shown in Fig. 13.

At both temperatures $(650 \mathrm{~K}$ and $900 \mathrm{~K}$ ), the major radical produced from triptane is C7H15-A due to the degeneracy effect where 9 hydrogens are available for abstraction at the A-site. The flux of $\mathrm{C} 7 \mathrm{H} 15-\mathrm{C}$ at low temperature is higher than $\mathrm{C} 7 \mathrm{H} 15-\mathrm{B}$, also because of the degeneracy effect. However, the flux moving toward $\mathrm{C} 7 \mathrm{H} 15-\mathrm{B}$ increases at $900 \mathrm{~K}$ (33\% at $900 \mathrm{~K}$ compared to $24 \%$ at $650 \mathrm{~K}$ ), where the $\mathrm{H}$-abstraction by $\mathrm{HO}_{2}$ radical is activated. $26 \%$ of the $\mathrm{C} 7 \mathrm{H} 15-\mathrm{B}$ radical produced at $900 \mathrm{~K}$ occurs by $\mathrm{H}$-abstraction by $\mathrm{HO}_{2}$.

At $650 \mathrm{~K}$, the main pathway for the triptyl radicals is addition to molecular oxygen and formation of peroxy radicals. Both primary peroxy radicals (C7H15-AO2 and $\mathrm{C} 7 \mathrm{H} 15-\mathrm{CO} 2)$ follow the 
isomerization pathway and produce hydroperoxy radicals (Q்OOH), while $77 \%$ of the tertiary peroxy radical (C7H15-BO2) experiences concerted elimination and forms triptene (TMBC7H14), consequently decreasing reactivity. This clarifies the negative sensitivity exhibited by the production of the tertiary triptyl radical (C7H15-B) as discussed in the previous section.

It is clear from the figure that isomers formed via a 6membered ring transition states are more favored, except $\mathrm{C} 7 \mathrm{H} 14-$ $\mathrm{ACOOH}$ which is formed via a 7-membered ring transition state. This is attributable to the additional hydrogens available for intermolecular migration at this site. The hydroperoxy radicals then either add to molecular oxygen (2nd $\mathrm{O}_{2}$ addition) producing peroxy hydroperoxy alkyl radicals ( $\mathrm{OOQOOH})$, or they form cyclic ethers. The formation of cyclic ethers is sometimes favored in highly branched alkanes, as has been discussed in our previous work on iso-octane [12]. This is because cyclic ether formation is favored when branching increases, and the thermodynamic stability of OOQOOH species with a radical on a primary site is lower. The main pathway for $\mathrm{OOQOOH}$ is the alternative isomerization where again isomers formed through 6-membered ring transition state are more favored. Only C7H14OOH-CCO2 forms KHP (C7KETCC). Four species of OOQOOH are formed; C7H14OOH-BAO2 doesn't form KHP due to the absence of $\alpha$-hydrogens. A greater flux of $\mathrm{C} 7 \mathrm{H} 14 \mathrm{OOH}-\mathrm{CAO} 2$ goes to alternative isomerization because KHP is formed through a 7-membered ring transition state (less favored). Although KHP are formed through a 6 -membered ring transition state in case of $\mathrm{C} 7 \mathrm{H} 14 \mathrm{OOH}-\mathrm{ACO} 2$ and $\mathrm{C} 7 \mathrm{H} 14 \mathrm{OOH}-\mathrm{CCO} 2$, a greater flux goes to alternative isomerization due to degeneracy effect (i.e. more hydrogens available for alternative isomerization pathway).

Figure 13 shows that the beta-scission of the triptyl radicals becomes important at high temperature (900 K). Forty-four percent of C7H15-A and 70\% of C7H15-C take this pathway, where the scission of the quaternary-tertiary bond is favored due to the weakness of this bond. On the other hand, the peroxy radicals formed isomerize producing Q $\mathrm{OOH}$, like those produced at $650 \mathrm{~K}$. However, a larger flux experiences concerted elimination, where $84 \%$ of $\mathrm{C} 7 \mathrm{H} 15-\mathrm{BO} 2$ and $16 \%$ of $\mathrm{C} 7 \mathrm{H} 15-\mathrm{CO} 2$ produces triptene, compared to $77 \%$ and $0 \%$ at $650 \mathrm{~K}$, respectively. The $\mathrm{QOOH}$ then form cyclic ethers and the second addition to oxygen never occurs at $900 \mathrm{~K}$. This is due to the thermodynamic instability of $\mathrm{OOQOOH}$ radicals produced at such elevated temperature.

\section{Comparison of heptane isomers}

The effect of branching on reactivity can be clearly seen in heptane isomers: $n$-heptane (NC7H16), 2-methylhexane (C7H16-2) and 2,2,3-trimethylbutane (TMBC7H16). Generally, the more branched the molecule is, the less sites are available for isomerization, so that reactivity is decreased. Consequently, the research octane number (RON) for the three isomers is zero, 42 and 112 for $n$ heptane, 2 methylhexane and triptane; respectively.

Figure 14 shows the computed IDT for heptane isomers at 25 bar and the stoichiometric mixture in air. Simulations were conducted using CHEMKIN-PRO [51], with the new model presented in this work for triptane, and models by Mohamed et al. [19] and Zhang et al. [20] for 2-methylhexane and $n$-heptane, respectively.

The figure demonstrates that the more branched the molecule is, the longer is the IDT, which synchronizes with the measured RON values mentioned above. Moreover, the high-temperature chemistry for triptane starts at $800 \mathrm{~K}$, compared to $950 \mathrm{~K}$ for the other two isomers; this is attributed to the less pronounced low temperature chemistry of triptane.

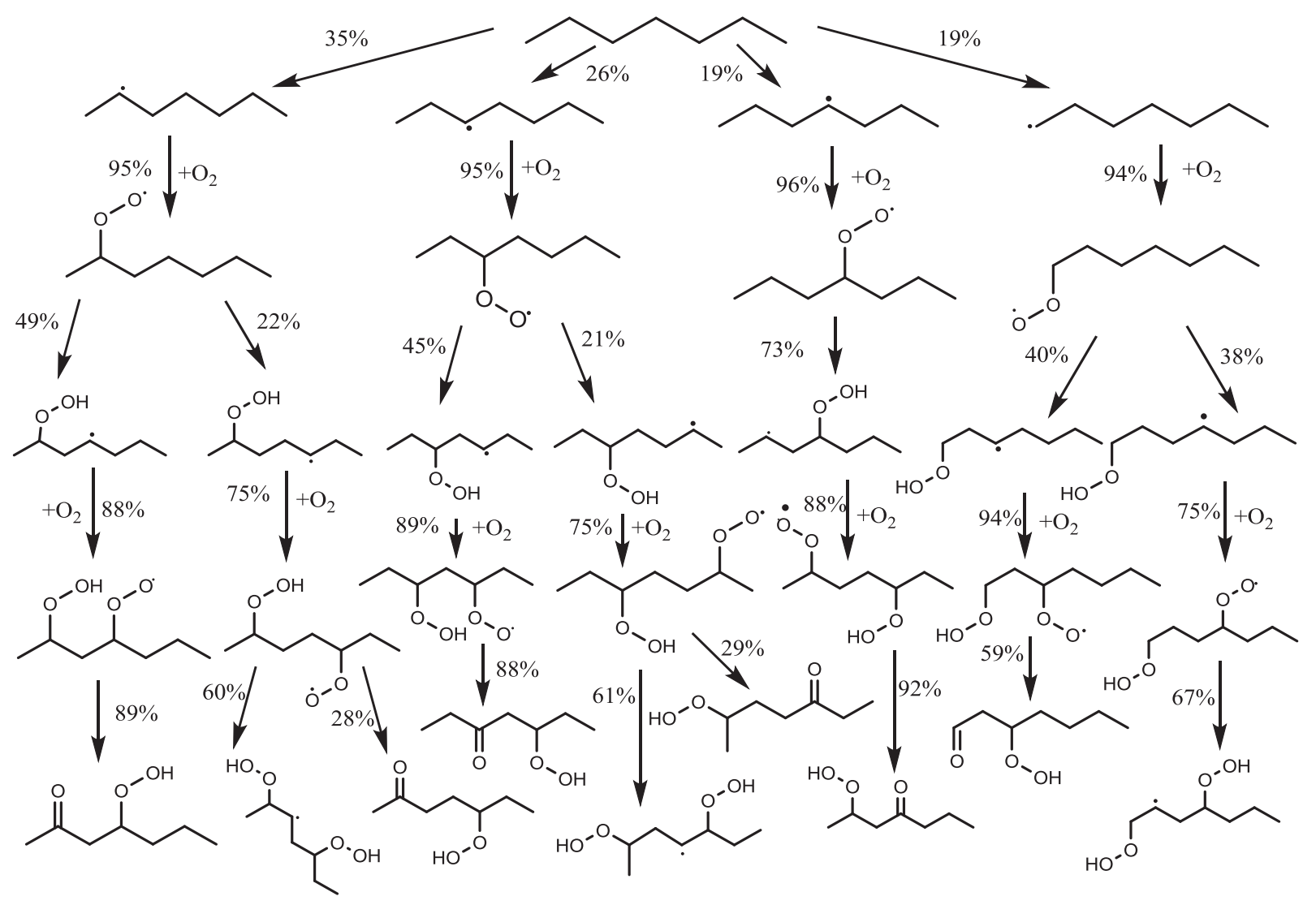

Fig. 16. ROP of stoichiometric n-heptane/air mixture at 20 bar and $750 \mathrm{~K}$. 
The simulated IDT of iso-octane $(\mathrm{RON}=100)$ using the model by Atef et al. [12] is also compared with the IDT of the heptane isomers in Fig. 14. The relative reactivity of iso-octane agrees with its RON; where it is more reactive than triptane and less reactive than $n$-heptane and 2-methylhexane. Similar to triptane, iso-octane exhibits less pronounced low temperature chemistry.

The difference in reactivity between $n$-heptane and triptane can be better understood by investigating the different pathways exhibited during the combustion of both fuels. Figure 15 presents the flux of stoichiometric triptane/air mixture at 25 bar and $750 \mathrm{~K}$. The analysis was conducted at $20 \%$ fuel consumption. It can be clearly seen that both $\mathrm{C} 7 \mathrm{H} 15-\mathrm{B}$ and $\mathrm{C} 7 \mathrm{H} 15-\mathrm{C}$ radicals end their pathways by forming cyclic ethers, which is a chain propagation pathway. Moreover, $80 \%$ of the tertiary peroxy radical experiences concerted elimination and forms an alkene, which also decreases reactivity. Only C7H15-A radical goes through the chain branching pathway and produces $\mathrm{KHP}$ and $\mathrm{P}(\mathrm{OOH})_{2}$.

Figure 16, on the other hand, shows the pathway for stoichiometric $n$-heptane/air mixture under the same conditions. It is apparent that all peroxy hydroperoxy-alky radicals (OOQOOH) go through the chain branching pathway, where they form either KHP or $\mathrm{P}(\mathrm{OOH})_{2}$. KHP is the main cause for the reactivity at low temperature in alkanes because the production of KHP from OOQOOH is accompanied by the release of $\dot{\mathrm{O}}$, and the subsequent dissociation of KHP releases another $\mathrm{OH}$. The formation of $\mathrm{P}(\mathrm{OOH})_{2}$ can be either a chain branching pathway in case it is followed by the formation of hydroperoxy cyclic ethers or it can be a chain propagation pathway and produces hydroperoxy olefins.

Interestingly, an overlap in the reactivity can be seen at $1000 \mathrm{~K}$, where the reactivity of triptane increases over the other isomers. This is attributed to the lower $\mathrm{C}-\mathrm{C}$ bond energies in the triptane molecule compared to the other isomers. This results in the early activation of the unimolecular decomposition reactions at such relatively low temperature $(1000 \mathrm{~K})$.

\section{Conclusions}

A new combustion model for triptane, a bio-derived octane booster, was developed in this work. The thermochemical properties of all species were created using new group values, with careful treatment of gauche interactions. Both high and low temperature reaction classes were included in the model, using analogous rates from the literature. The alternative isomerization pathway was also incorporated in the model. The model was able to reproduce a wide range of experimental data from RCM, ST and JSR. Some discrepancies were observed at high temperature, which might be attributed to the uncertainty in the rate of unimolecular decomposition of triptane.

Both experimental and simulation ignition delay data showed less-pronounced low temperature chemistry of triptane as a results of its highly branched structure. Sensitivity and rate of production analyses were also conducted to better understand the mechanism of triptane oxidation. It was found that $\mathrm{H}$-abstractions by $\dot{\mathrm{O}} \mathrm{H}$ are the most sensitive reactions at all investigated temperatures, where abstraction from primary sites increases reactivity while abstraction from the tertiary site decreases reactivity. The rate of production showed that the tertiary peroxy radical mainly undergoes concerted elimination and thereby decreases the reactivity. Moreover, most of the OOQOOH follows alternative isomerization pathway, which highlights the importance of this pathway for highly branched alkanes. Finally, the model was used to clarify the effect of branching on the reactivity of different isomers. It was seen that the high temperature region starts at lower temperatures in triptane compared to its less branched isomers, 2-methylhexane and $n$-heptane. Rate of production analysis showed that the main pathway during $n$-heptane oxidation is the second addition to molecular oxygen, while cyclic ethers are produced in triptane oxidation.

The effect of triptane addition on primary reference fuels (PRF) at engine relevant conditions should be investigated in the future. The model presented herein can help to understand the chemistry behind triptane as an octane booster.

\section{Acknowledgments}

This work was supported by the KAUST Clean Fuels Consortium (KCFC) and its member companies.

\section{Supplementary materials}

Supplementary material associated with this article can be found, in the online version, at doi:10.1016/j.combustflame.2019.09. 006 .

\section{References}

[1] S.M. Sarathy, A. Farooq, G.T. Kalghatgi, Recent progress in gasoline surrogate fuels, Prog. Energy Combust. Sci. 65 (2018) 67-108.

[2] G.T. Kalghatgi, Developments in internal combustion engines and implications for combustion science and future transport fuels, Proc. Combust. Inst. 35 (2015) 101-115

[3] W. Leitner, J. Klankermayer, S. Pischinger, H. Pitsch, K. Kohse-Höinghaus, Advanced biofuels and beyond: chemistry solutions for propulsion and production, Angew. Chem. Int. Ed. 56 (2017) 5412-5452.

[4] S.M. Sarathy, P. Oßwald, N. Hansen, K. Kohse-Höinghaus, Alcohol combustion chemistry, Prog. Energy Combust. Sci. 44 (2014) 40-102.

[5] B. Zhang, S.M. Sarathy, Lifecycle optimized ethanol-gasoline blends for turbocharged engines, Appl. Energy 181 (2016) 38-53.

[6] S.M. Sarathy, Fuel class higher alcohols, in: D.M. Boot (Ed.), Biofuels from lignocellulosic biomass, Wiley-VCH, Germany, 2016.

[7] D.A. Simonetti, J.H. Ahn, E. Iglesia, Mechanistic details of acid-catalyzed reactions and their role in the selective synthesis of triptane and isobutane from dimethyl ether, J. Catal. 277 (2011) 173-195.

[8] D.A. Simonetti, J.H. Ahn, E. Iglesia, Catalytic co-homologation of alkanes and dimethyl ether and promotion by adamantane as a hydride transfer co-catalyst, ChemCatChem 3 (2011) 704-718.

[9] J.A. Schaidle, D.A. Ruddy, S.E. Habas, M. Pan, G. Zhang, J.T. Miller, J.E. Hensley, Conversion of dimethyl ether to 2,2,3-trimethylbutane over a Cu/BEA catalyst: role of Cu sites in hydrogen incorporation, ACS Catal. 5 (2015) 1794-1803.

[10] J.T. Farrell, J. Holladay, R. Wagner, Co-optimization of fuels \& engines: fuel blendstocks with the potential to optimize future gasoline engine performance; identification of five chemical families for detailed evaluation, National Renewable Energy Lab. (NREL), Golden, CO, United States, 2018, 2018.

[11] C.K. Westbrook, W.J. Pitz, J.E. Boercker, H.J. Curran, J.F. Griffiths, C. Mohamed, M. Ribaucour, Detailed chemical kinetic reaction mechanisms for autoignition of isomers of heptane under rapid compression, Proc. Combust. Inst. 29 (2002) $1311-1318$.

[12] N. Atef, G. Kukkadapu, S.Y. Mohamed, M.A. Rashidi, C. Banyon, M. Mehl, K.A. Heufer, E.F. Nasir, A. Alfazazi, A.K. Das, C.K. Westbrook, W.J. Pitz, T. Lu, A. Farooq, C.-J. Sung, H.J. Curran, S.M. Sarathy, A comprehensive iso-octane combustion model with improved thermochemistry and chemical kinetics, Combust. Flame 178 (2017) 111-134.

[13] S.M. Villano, L.K. Huynh, H.H. Carstensen, A.M. Dean, High-pressure rate rules for alkyl $+\mathrm{O}_{2}$ reactions. 2. The isomerization, cyclic ether formation, and beta-scission reactions of hydroperoxy alkyl radicals, J. Phys. Chem. A 116 (2012) 5068-5089.

[14] S.M. Villano, L.K. Huynh, H.-H. Carstensen, A.M. Dean, High-pressure rate rules for alkyl $+\mathrm{O}_{2}$ reactions. 1 . The dissociation, concerted elimination, and isomerization channels of the alkyl peroxy radical, J. Phys. Chem. A 115 (2011) 13425-13442.

[15] S. Sharma, S. Raman, W.H. Green, Intramolecular hydrogen migration in alkylperoxy and hydroperoxyalkylperoxy radicals: accurate treatment of hindered rotors, J. Phys. Chem. A 114 (2010) 5689-5701.

[16] A. Miyoshi, Systematic computational study on the unimolecular reactions of alkylperoxy (RO2), hydroperoxyalkyl (QOOH), and hydroperoxyalkylperoxy (O2QOOH) radicals, J. Phys. Chem. A 115 (2011) 3301-3325.

[17] K. Zhang, C. Banyon, C. Togbé, P. Dagaut, J. Bugler, H.J. Curran, An experimental and kinetic modeling study of n-hexane oxidation, Combust. Flame 162 (2015) 4194-4207. 
[18] J. Bugler, B. Marks, O. Mathieu, R. Archuleta, A. Camou, C. Grégoire, K.A. Heufer, E.L. Petersen, H.J. Curran, An ignition delay time and chemical kinetic modeling study of the pentane isomers, Combust. Flame 163 (2016) 138-156.

[19] S.Y. Mohamed, L. Cai, F. Khaled, C. Banyon, Z. Wang, M.J. Al Rashidi, H. Pitsch, H.J. Curran, A. Farooq, S.M. Sarathy, Modeling ignition of a heptane isomer: improved thermodynamics, reaction pathways, kinetics, and rate rule optimizations for 2-methylhexane, J. Phys. Chem. A 120 (2016) 2201-2217.

[20] K. Zhang, C. Banyon, J. Bugler, H.J. Curran, A. Rodriguez, O. Herbinet, F. Battin-Leclerc, C. B'Chir, K.A. Heufer, An updated experimental and kinetic modeling study of n-heptane oxidation, Combust. Flame 172 (2016) 116-135.

[21] C.-W. Zhou, Y. Li, E. O’Connor, K.P. Somers, S. Thion, C. Keesee, O. Mathieu, E.L. Petersen, T.A. DeVerter, M.A. Oehlschlaeger, G. Kukkadapu, C.-J. Sung, M. Alrefae, F. Khaled, A. Farooq, P. Dirrenberger, P.-A. Glaude, F. Battin-Leclerc, J. Santner, Y. Ju, T. Held, F.M. Haas, F.L. Dryer, H.J. Curran, A comprehensive experimental and modeling study of isobutene oxidation, Combust. Flame 167 (2016) 353-379.

[22] R. Fang, G. Kukkadapu, M. Wang, S.W. Wagnon, K. Zhang, M. Mehl, C.K. Westbrook, W.J. Pitz, C.-J. Sung, Autoignition experiments and kinetic modeling of selected highly-branched C8-C16 iso-alkanes for surrogate fuel applications, 11th US National Combustion Meeting, Pasedena, CA, United States (2019).

[23] Y. Zhang, K.P. Somers, M. Mehl, W.J. Pitz, R.F. Cracknell, H.J. Curran, Probing the antagonistic effect of toluene as a component in surrogate fuel models at low temperatures and high pressures. a case study of toluene/dimethyl ether mixtures, Proc. Combust. Inst. 36 (2017) 413-421.

[24] W.B. Sidney, Thermochemical kinetics: methods for the estimation of thermochemical data and rate parameters, 2nd ed., John Wiley \& Sons, 1976.

[25] E.R. Ritter, THERM: a computer code for estimating thermodynamic properties for species important to combustion and reaction modeling, J. Chem. Inf. Comput. Sci. 31 (1991) 400-408.

[26] S.M. Burke, J.M. Simmie, H.J. Curran, Critical evaluation of thermochemical properties of $\mathrm{C} 1-\mathrm{C} 4$ species: updated group-contributions to estimate thermochemical properties, J. Phys. Chem. Ref. Data 44 (2015) 013101.

[27] J.M. Simmie, K.P. Somers, Benchmarking compound methods (CBS-QB3, CBS-APNO, G3, G4, W1BD) against the active thermochemical tables: a litmus test for cost-effective molecular formation enthalpies, J. Phys. Chem. A 119 (2015) 7235-7246.

[28] M.K. Sabbe, M. Saeys, M.-F. Reyniers, G.B. Marin, V. Van Speybroeck, M. Waroquier, Group additive values for the gas phase standard enthalpy of formation of hydrocarbons and hydrocarbon radicals, J. Phys. Chem. A 109 (2005) $7466-7480$.

[29] S.M. Sarathy, C.K. Westbrook, M. Mehl, W.J. Pitz, C. Togbe, P. Dagaut, H. Wang, M.A. Oehlschlaeger, U. Niemann, K. Seshadri, P.S. Veloo, C. Ji, F.N. Egolfopoulos, $\mathrm{T}$. Lu, Comprehensive chemical kinetic modeling of the oxidation of 2-methylalkanes from C7 to C20, Combust. Flame 158 (2011) 2338-2357.

[30] W. Wang, Z. Li, M.A. Oehlschlaeger, D. Healy, H.J. Curran, S.M. Sarathy, M. Mehl, W.J. Pitz, C.K. Westbrook, An experimental and modeling study of the autoignition of 3-methylheptane, Proc. Combust. Inst. 34 (2013) 335-343.

[31] F. Karsenty, S.M. Sarathy, C. Togbé, C.K. Westbrook, G. Dayma, P. Dagaut, M. Mehl, W.J. Pitz, Experimental and kinetic modeling study of 3-methylheptane in a jet-stirred reactor, Energy Fuels 26 (2012) 4680-4689.

[32] S.M. Sarathy, T. Javed, F. Karsenty, A. Heufer, W. Wang, S. Park, A. Elwardany, A. Farooq, C.K. Westbrook, W.J. Pitz, M.A. Oehlschlaeger, G. Dayma, H.J. Curran, P. Dagaut, A comprehensive combustion chemistry study of 2,5-dimethylhexane, Combust. Flame 161 (2014) 1444-1459.

[33] C.K. Westbrook, W.J. Pitz, H.C. Curran, J. Boercker, E. Kunrath, Chemical kinetic modeling study of shock tube ignition of heptane isomers, Int. J. Chem. Kinet. 33 (2001) 868-877.

[34] M. Evans, M. Polanyi, Inertia and driving force of chemical reactions, Trans. Faraday Soc. 34 (1938) 11-24.

[35] H. Ning, C. Gong, Z. Li, X. Li, Pressure-dependent kinetics of initial reactions in iso-octane pyrolysis, J. Phys. Chem. A 119 (2015) 4093-4107.
[36] M.J. Frisch, G.W. Trucks, H.B. Schlegel, G.E. Scuseria, M.A. Robb, J.R. Cheeseman, G. Scalmani, V. Barone, B. Mennucci, G.A. Petersson, H. Nakatsuji, M. Caricato, X. Li, H.P. Hratchian, A.F. Izmaylov, J. Bloino, G. Zheng, J.L. Sonnenberg, M. Hada, M. Ehara, K. Toyota, R. Fukuda, J. Hasegawa, M. Ishida, T. Nakajima, Y. Honda, O. Kitao, H. Nakai, T. Vreven, J.A. Montgomery Jr. J.E. Peralta, F. Ogliaro, M.J. Bearpark, J. Heyd, E.N. Brothers, K.N. Kudin, V.N. Staroverov, R. Kobayashi, J. Normand, K. Raghavachari, A.P. Rendell, J.C. Burant, S.S. Iyengar, J. Tomasi, M. Cossi, N. Rega, N.J. Millam, M. Klene, J.E. Knox, J.B. Cross, V. Bakken, C. Adamo, J. Jaramillo, R. Gomperts, R.E. Stratmann, O. Yazyev, A.J. Austin, R. Cammi, C. Pomelli, J.W. Ochterski, R.L. Martin, K. Morokuma, V.G. Zakrzewski, G.A. Voth, P. Salvador, J.J. Dannenberg, S. Dapprich, A.D. Daniels, Ö. Farkas, J.B. Foresman, J.V. Ortiz, J. Cioslowski, D.J. Fox, Gaussian 09, Gaussian, Inc., Wallingford, CT, USA, 2009.

[37] R. Sivaramakrishnan, J.V. Michael, Rate constants for oh with selected large alkanes: shock-tube measurements and an improved group scheme, J. Phys. Chem. A 113 (2009) 5047-5060.

[38] D. Liu, F. Khaled, B.R. Giri, E. Assaf, C. Fittschen, A. Farooq, H-Abstraction by $\mathrm{OH}$ from large branched alkanes: overall rate measurements and site-specific tertiary rate calculations, J. Phys. Chem. A 121 (2017) 927-937.

[39] J. Badra, A. Farooq, Site-specific reaction rate constant measurements for various secondary and tertiary $\mathrm{H}$-abstraction by $\mathrm{OH}$ radicals, Combust. Flame 162 (2015) 2034-2044

[40] C.F. Goldsmith, W.H. Green, S.J. Klippenstein, Role of $\mathrm{O}_{2}+\mathrm{QOOH}$ in low-temperature ignition of propane. 1. Temperature and pressure dependent rate coefficients, J. Phys. Chem. A 116 (2012) 3325-3346.

[41] S. Snitsiriwat, J.W. Bozzelli, Thermochemistry, reaction paths, and kinetics on the tert-isooctane radical reaction with $\mathrm{O}_{2}$, J. Phys. Chem. A 118 (2014) 4631-4646.

[42] H.J. Curran, P. Gaffuri, W.J. Pitz, C.K. Westbrook, A comprehensive modeling study of n-heptane oxidation, Combust. Flame 114 (1998) 149-177.

[43] H.J. Curran, P. Gaffuri, W.J. Pitz, C.K. Westbrook, A comprehensive modeling study of iso-octane oxidation, Combust. Flame 129 (2002) 253-280.

[44] S.M. Burke, U. Burke, R. Mc Donagh, O. Mathieu, I. Osorio, C. Keesee, A. Morones, E.L. Petersen, W. Wang, T.A. DeVerter, An experimental and modeling study of propene oxidation. Part 2: ignition delay time and flame speed measurements, Combust. Flame 162 (2015) 296-314.

[45] L. Brett, J. Macnamara, P. Musch, J.M. Simmie, Simulation of methane autoignition in a rapid compression machine with creviced pistons, Combust. Flame 124 (2001) 326-329.

[46] C. Lee, A. Ahmed, E.F. Nasir, J. Badra, G. Kalghatgi, S.M. Sarathy, H. Curran, A. Farooq, Autoignition characteristics of oxygenated gasolines, Combust. Flame 186 (2017) 114-128.

[47] D. Darcy, H. Nakamura, C.J. Tobin, M. Mehl, W.K. Metcalfe, W.J. Pitz, C.K. Westbrook, H.J. Curran, A high-pressure rapid compression machine study of n-propylbenzene ignition, Combust. Flame 161 (2014) 65-74.

[48] J. Badra, A.E. Elwardany, F. Khaled, S.S. Vasu, A. Farooq, A shock tube and laser absorption study of ignition delay times and $\mathrm{OH}$ reaction rates of ketones: 2-Butanone and 3-buten-2-one, Combust. Flame 161 (2014) 725-734.

[49] B. Chen, C. Togbé, Z. Wang, P. Dagaut, S.M. Sarathy, Jet-stirred reactor oxidation of alkane-rich face gasoline fuels, Proc. Combust. Inst. 36 (2017) 517-524.

[50] B. Chen, Z. Wang, J.-Y. Wang, H. Wang, C. Togbé, P.E.Á. Alonso, M. Almalki, M. Mehl, W.J. Pitz, S.W. Wagnon, K. Zhang, G. Kukkadapu, P. Dagaut, S.Mani Sarathy, Exploring gasoline oxidation chemistry in jet stirred reactors, Fuel 236 (2019) 1282-1292.

[51] R. Design, CHEMKIN-PRO, 15112, Reaction Design, San Diego, CA, 2011.

[52] C.-W. Zhou, Y. Li, U. Burke, C. Banyon, K.P. Somers, S. Ding, S. Khan, J.W. Hargis, T. Sikes, O. Mathieu, E.L. Petersen, M. AlAbbad, A. Farooq, Y. Pan, Y. Zhang, Z. Huang, J. Lopez, Z. Loparo, S.S. Vasu, H.J. Curran, An experimental and chemical kinetic modeling study of 1,3-butadiene combustion: ignition delay time and laminar flame speed measurements, Combust. Flame 197 (2018) 423-438. 